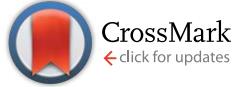

Cite this: J. Mater. Chem. A, 2015, 3, 17290

Received 9th July 2015

Accepted 27th July 2015

DOI: $10.1039 / c 5 t a 05162 b$

www.rsc.org/MaterialsA

\section{Hygrothermal simulation-informed design of mesoporous desiccants for optimised energy efficiency of mixed mode air conditioning systems}

\begin{abstract}
Fernando Sarce Thomann, ${ }^{\star a}$ Matthew R. Hall, ${ }^{\text {ab }}$ Robert Mokaya ${ }^{c}$ and Lee A. Stevens ${ }^{a}$
This paper describes an optimization technique using hygrothermal numerical modelling to determine an ideal and unknown isotherm in order to inform the design of optimised mesoporous desiccants. Their suitability for passive humidity buffering as well as their impact on energy efficiency was assessed when assisting a mixed mode air-conditioning (AC) system. Three clear stages of water vapour adsorption were found that strongly correspond to the $\Delta w$ gradient when assessing the kinetics of adsorption and exchange rates for periodic moisture loads. Consistent agreement was found between the latent heat of dehumidification used by the AC system and the desiccant decay time after successive sorption loop cycles. This confirmed the material's suitability for specific applications and was found to be highly sensitive to the portion of the isotherm between $\varphi_{i, L}-\varphi_{i, U}(\Delta W$ gradient), compared with full adsorption capacity (total $w$ ) when assessing total energy consumption. The experimental results of sorption kinetics appeared to be slightly underestimated between the $\Delta w$ gradient and the response time to reach equilibrium moisture content (EMC). The major underestimations were found to be consistent with the kinetics of adsorption/desorption when analysing their significance based on $w$ differences. These were largely attributed to a combination of adsorption kinetics (time-response) and adsorption/desorption hysteresis. However, this was not evident when comparing long-term experimental data and numerical estimations for water vapour sorption isotherms, since numerical model accurately predicted them. This suggests that both adsorption kinetics and the scanning curve prediction, within a hysteresis loop, are not accurately represented by current hygrothermal models and are hence a priority for future research.
\end{abstract}

\section{Introduction}

Desiccant material performance is typically assessed with respect to isotherm characteristics and target application., This implies that the criteria for optimisation are dependent upon the thermal and moisture loads, and operating parameters, inside the closed environment being studied. Optimised mesoporous desiccants can be used to passively regulate indoor dry bulb temperature and relative humidity in closed environments, and to reduce the energy penalty of mechanical heating, ventilation and air conditioning (HVAC)., ${ }^{3,4}$ Traditional refrigerant vapour compressor systems (VCS) used for regulating the interior psychrometric conditions of 'closed environments' (e.g., offices, hospitals, laboratories, industry, etc.) are responsible for a large amount of energy consumption with associated

${ }^{a}$ Division of Materials, Mechanics and Structures, Faculty of Engineering, University of Nottingham, University Park, Nottingham, NG7 2RD, UK. E-mail: emxfs@nottingham. ac.uk; Tel: +44 (0)115 8467873

${ }^{b}$ British Geological Survey, Environmental Science Centre, Keyworth, Nottingham, NG12 5GG, UK

${ }^{c}$ School of Chemistry, University of Nottingham, University Park, Nottingham, NG7 $2 R D, U K$ greenhouse gas emissions. ${ }^{5-8}$ The study of desiccants as dehumidifier materials in the air-conditioning (AC) industry has attracted the interest of many researchers in the last decades. ${ }^{\mathbf{9}-13}$ This has primarily motivated the understanding their abilities to reduce the 'energy penalties' caused by mechanical air dehumidification (latent heat), and the required energy to reheat the air up to the supply air temperature (sensible heat), by engineering their water adsorption/retention properties. ${ }^{\mathbf{1 4 - 1 7}}$ Some examples of desiccant implementation are included in (i) AC mixed mode systems, ${ }^{\mathbf{1 8}, 19}$ (ii) evaporative cooling technology for high humidity climates, ${ }^{20,21}$ (iii) regulating indoor thermal comfort, ${ }^{22-24}$ (iv) as a solid-desiccant in solar AC systems, ${ }^{25-28}$ (v) indirect evaporative cooling systems, ${ }^{29,30}$ and (vi) waste heat transformation applications for absorption chillers and heat pumps. $^{31-34}$

As an alternative to traditional VCS cooling technologies, solid-desiccant cooling systems (SDC) have motivated the investigation of advanced desiccant materials since their characteristics (water adsorption behaviour, regeneration capacity, and long-term stability) play an important role in their performance and efficiency. ${ }^{35,36}$ These have been organized into three main categories: ${ }^{37}$ (i) composite desiccants (i.e., silica-based, mesoporous silicate-based and carbon-based), (ii) nanoporous 
inorganic materials (i.e., aluminosilicate zeolites, aluminophosphates, and aerogels), and (iii) polymeric desiccants (i.e., metal-organic frameworks (MOFs) and polyelectrolyte). Ongoing research ${ }^{38-42}$ has been focused on the preparation of these materials with improved water adsorption characteristics which include high surface area, large pore volume and an unprecedented physicochemical variability. This, in the case of MCM-41 and SBA-15, has been possible due to the modulation of their textural properties through the synthesis process by controlling temperature ${ }^{43,44}$ and reaction time..$^{45,46}$ These mesoporous materials exhibit enhanced water adsorption properties compared with those traditional silica-based as a result of having regular pore structures and high surfaces areas. ${ }^{47}$ On the other hand, significant interest has been focussed on MOFs as water adsorbents due to their large adsorption capacity, fine-tunable pore size, high surface area, and pore volume controlled by change in organic ligands and metal subunits. ${ }^{48-51}$ In recent work done by Furukawa et al. ${ }^{52}$ large water adsorption capacity and pore volume $\left(735-850 \mathrm{~cm}^{3} \mathrm{~g}^{-1}\right.$ and $0.88 \mathrm{~cm}^{3} \mathrm{~g}^{-1}$, respectively) was reported from low to high $p_{\mathrm{v}} / p_{0}$ range (0.05-0.7). Their MOF materials exhibited outstanding sorption/desorption water uptake after 5 cycles (showing no loss of porosity) at a low regeneration temperature $\left(25^{\circ} \mathrm{C}\right)$. In addition, studies done in Materials of Institute Lavoisier (MIL) frameworks showed even greater values of water adsorption $\left(1.06-1.7 \mathrm{~cm}^{3} \mathrm{~g}^{-1}\right)$ and large pore volume $\left(1.4-1.58 \mathrm{~cm}^{3} \mathrm{~g}^{-1}\right)^{53-55}$ with low regeneration temperature $\left(30^{\circ} \mathrm{C}\right)$, and rapid-response rates of $40 \%$ weight loss after only 30 minutes at $30{ }^{\circ} \mathrm{C} .{ }^{55} \mathrm{It}$ is expected that desirable properties in an optimal desiccant material are therefore not only its water adsorption capacity (and isotherm type), but also their rate of sorption/desorption (kinetic stability) at a defined regeneration temperature.

All of these desiccants have currently only been analysed in terms of full adsorption capacity (i.e., independent of isotherm shape) with the intention of producing large pore volumes, and have not assessed their suitability for specific applications. In order to do this an understanding of the isotherm shape at particular $p_{\mathrm{v}} / p_{0}$ ranges is required, as well as their transient response to changes in ambient vapour pressure, $\Delta p_{\mathrm{v}}$. If understood, advanced desiccant materials could then be used to partially or even fully regulate the fluctuations of RH and to allow reduction in energy penalties when tailoring and optimizing their isotherm shape for regulating 'specific' psychrometric requirements of closed environments. Therefore, the aim of this study was to apply a numerical hygrothermal approach (from our previous work ${ }^{56}$ ) to determine the ideal (and unknown) water vapour isotherm to inform the design of optimised mesoporous desiccants. The isotherms were then experimentally re-created through synthesis and modulation of well-known mesoporous material classes (MCM-41 and SBA 15). The material's suitability for regulating indoor $\mathrm{RH}$, in terms of dehumidification load reductions (enthalpy), were assessed after different moisture loads had been introduced. They were then assessed to enable the relative effect on energy efficiency when assisting a mixed mode air conditioning (AC) system. The sorption/desorption kinetic response of selected traditional and advanced desiccants will be then assessed experimentally.

\section{Experimental section}

\subsection{Desiccant candidates}

A set of ten candidate desiccants (see Fig. 1) were selected as part of a representative group of mesoporous materials, as defined by IUPAC. ${ }^{57}$ The aim was to assess their capacity for buffering humidity ratio fluctuations (and hence indoor air enthalpy) within specific closed environment scenarios. In recent work a principle was established which defined the available moisture capacity, $\Delta w$ for $\mathrm{RH}$ buffering within a specific operating range. ${ }^{56}$ Therefore, the region of interest among the isotherm candidates was defined between point $b$ seen in Fig. 2a (1st inflection point; the onset of multilayer physisorption) and point $c$ (2nd inflection point; the percolation threshold). The capillary transport coefficients $\left(D_{\mathrm{ws}}\right.$ and $\left.D_{\mathrm{ww}}\right)$ were calculated from each isotherm, ${ }^{58}$ and the water adsorption coefficient, $A$ was assumed constant for all materials based on assumptions established from previous work. ${ }^{38}$

\subsection{Synthesis and characterization}

Synthesis and the textural properties of the pure silica MCM41@165 were obtained using same experimental description of our previous work. ${ }^{56}$ Synthesis of SBA-15 (6 nm pore size) was prepared in a similar manner to Zhao et al. ${ }^{59}$ with the same batch of SBA-15 used throughout the study. Pluronic 123 (P123, triblock copolymer (EO)20(PO)70(EO)20, $80.0 \mathrm{~g}$ ) was dissolved in aqueous hydrochloric acid $(1.33 \mathrm{M}, 3000 \mathrm{ml})$ with vigorous stirring at $35{ }^{\circ} \mathrm{C}$. After complete dissolution tetraethoxyorthosilicate (TEOS, $182 \mathrm{ml}$ ) was added dropwise and the mixture stirred at $35^{\circ} \mathrm{C}$ for $24 \mathrm{~h}$. The solution was then statically heated at $85{ }^{\circ} \mathrm{C}$ for $48 \mathrm{~h}$. The resulting white solid was dried in an oven at $105{ }^{\circ} \mathrm{C}$ for $2 \mathrm{~h}$ before heating in a furnace to $600{ }^{\circ} \mathrm{C}$ for $6 \mathrm{~h}$ to obtain a white solid powder. Synthesis of SBA-15 (10 $\mathrm{nm}$ pore size) was prepared in a similar manner to Zhao et al. ${ }^{59}$

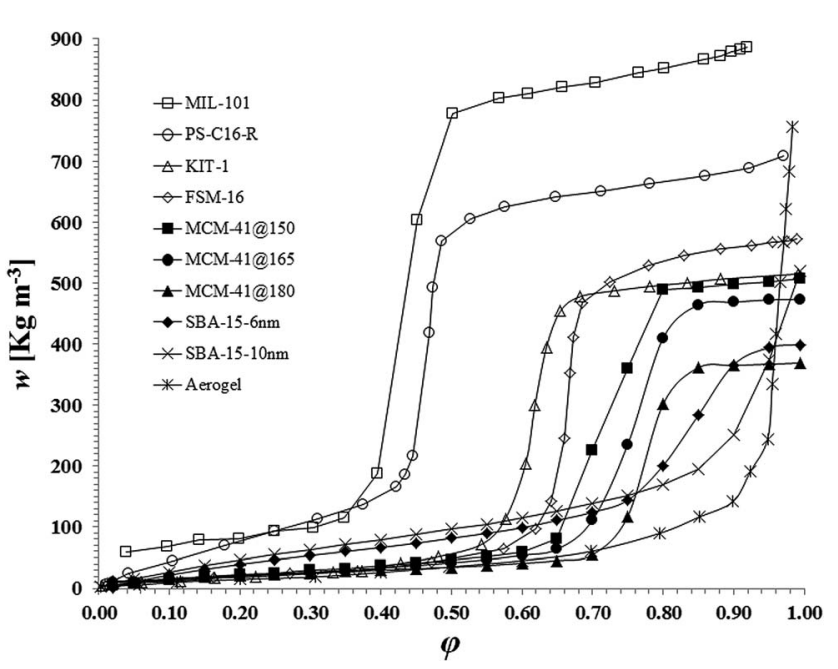

Fig. 1 Water vapour sorption isotherms for all desiccant candidates. References are provided for the following desiccants candidates: MIL$101,{ }^{66}$ PS-C16-R, ${ }^{67}$ KIT-1 and FSM-16, ${ }^{69}$ MCM-41@150 and 180, ${ }^{56}$ aerogel. ${ }^{68}$ The three water vapour isotherms from the new materials made (MCM-41@165, SBA-15 $6 \mathrm{~nm}$ and $10 \mathrm{~nm}$ ) are also provided. 

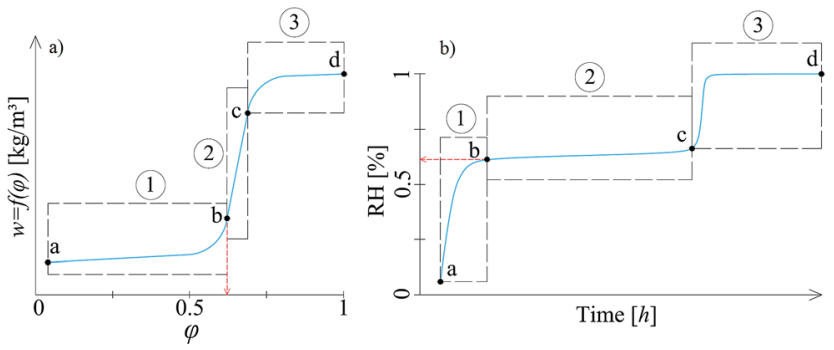

Fig. 2 (a) Schematic representation of a water vapour sorption isotherm portions at different EMC stages $a-b, b-c$ and $c-d$. (b) Corresponding water vapour sorption kinetics at different EMC stages $a-b, b-c$ and $c-d$ that shows EMC in the segments 1, 2 and 3.

Table 1 Textural properties summary for SBA-15 desiccant candidates

\begin{tabular}{llllr}
\hline Sample & $S_{\mathrm{BET}} / \mathrm{m}^{2} \mathrm{~g}^{-1}$ & $V_{\mathrm{m}} / \mathrm{cm}^{3} \mathrm{~g}^{-1}$ & $V_{\mathrm{p}} / \mathrm{cm}^{3} \mathrm{~g}^{-1}$ & $D_{\mathrm{p}} / \mathrm{nm}$ \\
\hline SBA-15 6 nm & 876 & 0.17 & 0.91 & 5.7 \\
SBA-15 $10 \mathrm{~nm}$ & 757 & 0.12 & 1.26 & 10.2 \\
\hline
\end{tabular}

with the same batch of SBA-15 used throughout the study. Pluronic 123 (P123, triblock copolymer (EO)20(PO)70(EO)20, $4.0 \mathrm{~g})$ was dissolved in aqueous hydrochloric acid $(1.33 \mathrm{M}$, $75 \mathrm{ml})$ and mesitylene $(2 \mathrm{ml})$ with vigorous stirring at $35{ }^{\circ} \mathrm{C}$. After complete dissolution tetraethoxyorthosilicate (TEOS, $4.55 \mathrm{ml}$ ) was added dropwise and the mixture stirred at $35^{\circ} \mathrm{C}$ for $24 \mathrm{~h}$. The solution was then placed in a Teflon lined autoclave and heated at $120^{\circ} \mathrm{C}$ for $24 \mathrm{~h}$. The resulting white solid was recovered and then in an oven at $105^{\circ} \mathrm{C}$ for $2 \mathrm{~h}$ before heating in a furnace at $600{ }^{\circ} \mathrm{C}$ for $6 \mathrm{~h}$ to obtain a white solid powder. Textural properties (see Table 1) were determined from $\mathrm{N}_{2}$ sorption analysis at $-196{ }^{\circ} \mathrm{C}$ using a Micromeritics ASAP 2020 analyser. Samples (approximately $0.2 \mathrm{~g}$ ) were outgassed prior to analysis under high vacuum at $120^{\circ} \mathrm{C}$ for $15 \mathrm{~h}$. Specific surface areas (SSA) was calculated using the standard BrunauerEmmett-Teller (SBET) method, micropore volume $\left(V_{\mathrm{m}}\right)$ by the tplot method with Harkins and Jura correction for thickness curve correction. Average pore diameter $\left(D_{\mathrm{p}}\right)$ was determined by the Barrett-Joyner-Halenda (BJH) method by applying a cylindrical pore model using Kelvin equation with Harkins and Jura for thickness curve correction. Nitrogen adsorption at relative pressure of 0.99 was taken as total pore volume $\left(V_{\mathrm{p}}\right)$.

\subsection{Dynamic vapour sorption (DVS)}

A gravimetric dynamic vapour sorption (DVS) test was performed to determine the water vapour isotherms for the candidate materials (MCM-41@165, SBA-15 6 nm and SBA-15 10 $\mathrm{nm}$ ). A DVS Advantage-2 series (Surface Measurements Systems Ltd, London, England) with incorporated ultra-microbalance (1 $\mu \mathrm{g}$ sensitivity) and fully automated weighing/purging was used to independently control $T_{\mathrm{db}}$ and RH to an accuracy of $\pm 0.5 \mathrm{~K}$ and $\pm 1.5 \%$, respectively (vapour pressure accuracy $\pm 1.5 \% p_{\mathrm{v}} /$ $p_{0}$ ). Advantage Control Software (ACS) was used to automatically record the data in $1 \mathrm{~min}$ time-steps. Before analysis, the samples were dried under vacuum at $120^{\circ} \mathrm{C}$ for $12 \mathrm{~h}$ to ensure removal of residual moisture. In order to ensure stability for baseline measurements accuracy, clean quartz sample and reference pan were left to fully equilibrate at $23^{\circ} \mathrm{C}$ at constant nitrogen flow (10 sccm 1 bar) for $1 \mathrm{~h}$ prior to the weighing and tared. Dry samples (approximately $0.2 \mathrm{~g}$ ) were weighed into the sample pan and allowed to equilibrate again under the carrier gas for $1 \mathrm{~h}$. After stability, the sample weight was recorded (initial mass $M_{0}$ ) and reference weight was set to zero with no counter weight. To ensure $w=0$, a pre-heating sequence was set from to 23 to $150{ }^{\circ} \mathrm{C}\left(2{ }^{\circ} \mathrm{C} \mathrm{min}^{-1}\right.$ ramp rate $)$ for $1 \mathrm{~h}$ prior to vapour dosing. A targeted relative vapour pressure from $\varphi=$ 0.05 to 1 ( $\varphi=0.05$ intervals) was programmed to sequentially increase in a 21-steps full cycle (sorption/desorption), where a change in mass step ( $0.001 \%$ per min) was set until EMC was achieved. This was performed at $T_{\mathrm{db}} 23{ }^{\circ} \mathrm{C}$ and to a constant water vapour flow rate of $100 \mathrm{sccm}$.

Three sets of experiments to assess the water vapour adsorption/desorption kinetics were performed. For this, a set of RH limits were defined $(20-30 \% ; 30-50 \%$; and $50-70 \%)$ and the kinetics of the moisture sorption began to sequentially fluctuate in an adsorption/desorption cycle. Each cycle comprised $2 \mathrm{~h}$ of moisture sorption (i.e., 30-50\% RH) followed by $2 \mathrm{~h}$ of moisture desorption (i.e., $50-30 \% \mathrm{RH}$ ) for a total period of $12 \mathrm{~h}$ ( 3 complete cycles). Prior to testing, all samples were outgassed under vacuum at $120{ }^{\circ} \mathrm{C}$ for $12 \mathrm{~h}$ and the preheating sequence was applied as described above. To ensure that EMC was achieved for the $w_{20}, w_{30}$ and $w_{50}$ set points, all samples were pre-conditioned within the DVS chamber before the cycles started. Taring and equilibration of the microbalance steps were done as previously described, where all samples $(\sim 0.02 \mathrm{~g})$ were loaded to define the initial mass $\left(M_{0}\right)$ in the DVS. This was performed at $T_{\mathrm{db}} 23{ }^{\circ} \mathrm{C}$ at a constant water vapour flow rate of $100 \mathrm{sccm}$, as with previous experiments.

\subsection{Hygrothermal numerical model}

A number of hygrothermal models packages have been validated over the past 15+ years against experimental data including (but not limited to) DELPHIN, HAM, MATCH and WUFI, as part of the Annex 41 project. ${ }^{60}$ To validate numerical model predictions for heat and mass transport/storage physical model are commonly used to simulate the bulk-scale of the hygrothermal behaviour of some functional material properties. ${ }^{61-63}$ As a minimum, all hygrothermal numerical models must accurately predict the following bulk-scale coupled phenomena of heat and mass transport/storage: ${ }^{64}$

- Heat storage in dry materials and any absorbed water.

- Heat transport by moisture-dependent thermal conduction.

- Latent heat transfer by vapour diffusion.

- Moisture storage by vapour sorption and capillary forces.

- Moisture transport by vapour diffusion.

- Moisture transport by liquid transport (surface diffusion and capillary flow).

For this study, the Wärme und Feuchte Instationär (WUFI) hygrothermal numerical model, ${ }^{65}$ WUFI+ v2.5.3 (Fraunhofer, Germany), was used. The governing equation that represents the moisture storage function is seen in the LHS of eqn (1), 
which is proportional to the derivative of the water adsorption isotherm $(\partial w / \partial \varphi)$. The transport terms on the RHS of eqn (1) are described by the divergence of liquid and vapour diffusion with phase changes strongly dependent on the moisture fields and fluxes. Whilst the driving potential for vapour flux, which is vapour pressure $\left(p_{\mathrm{v}}=\varphi \times p_{\text {sat }}\right)$, is strongly temperaturedependent (saturation pressure $p_{\text {sat }} \sim \exp (T)$ ). The liquid flow, on the other hand, is governed by differences in capillary forces which are assumed to be a function of RH only (i.e., from Kelvin condensation). The storage term seen in LHS of eqn (2) describes the vapour enthalpy of air flow inside the closed environment, whilst the RHS describes heat transport due to solid conduction and diffusion of heat associated with the specific enthalpy of vapour water.

$$
\begin{gathered}
\text { Moisture balance }: \frac{\mathrm{d} w}{\mathrm{~d} \varphi} \frac{\partial \varphi}{\partial t}=\nabla\left(D_{\mathrm{w}} \nabla \varphi+\delta_{\mathrm{p}} \nabla\left(\varphi p_{\text {sat }}\right)\right) \\
\text { Energy balance : } \frac{\mathrm{d} H}{\mathrm{~d} T} \frac{\partial T}{\partial t}=\nabla(\lambda \nabla T)+h_{\mathrm{v}} \nabla\left(\delta_{\mathrm{p}} \nabla\left(\varphi p_{\text {sat }}\right)\right)
\end{gathered}
$$

\subsection{Sensitivity analysis}

Sensitivity analysis was conducted to assess the water vapour adsorption behaviour (capacity) and water vapour exchange performance for all candidate materials in a closed environment where the initial moisture content was $w=0$. The hygrothermal numerical model was setup to sequentially perform water vapour adsorption simulations between the operating limits $\varphi_{\min }=0$ and $\varphi_{\max }=0.95$. A moisture generation rate of $3 \mathrm{~g} \mathrm{~h}^{-1}$ per $24 \mathrm{~h}$ period with and an air infiltration rate of $0.35 \mathrm{ACH} \mathrm{h}{ }^{-1}$ were set. The water vapour exchange rate was then estimated as the fraction of cumulative moisture load per hour. The closed environment comprised a thermally and hygrically isolated box (where $V=1 \mathrm{~m}^{3}$ ) with the initial boundary conditions (interior/exterior) were set at $\varphi_{\mathrm{i}}=0$ and $\varphi_{\mathrm{e}}$ $=0.95$ under isothermal conditions, $T_{\mathrm{db}}=23{ }^{\circ} \mathrm{C}$. The fabric of the envelope comprised a $2 \mathrm{~mm}$ thick vapour barrier $\left(S_{\mathrm{d}}=1500\right.$ $\mathrm{m})$ and $240 \mathrm{~mm}$ thick vacuum insulation panel $(\lambda=0.001)$. A non-visualized internal component was defined (area/volume ratio $=0.4048 \mathrm{~m}^{2}$, equivalent to $\sim 500 \mathrm{~g}$ ) comprising $2 \mathrm{~mm}$ thickness of candidate material and using the hygrothermal functional properties detailed in Table 2. These were gathered from previous research, ${ }^{38}$ where pore geometry and specific surface area were obtained using the BJH and BET method with $\mathrm{N}_{2}$ physisorption. Validation against high resolution transmission electron microscopy (HRTEM) and small-angle X-ray diffraction (SAXRD) were conducted. Modified transient plane source (MTPS), differential scanning calorimetry (DSC) and dynamic vapour sorption techniques were used to determine the hygrothermal functional properties. The numerical model was solved using (i) increased accuracy and adapted convergence options, (ii) time step $1 \mathrm{~min}$, 'fine' mesh grid spacing, and (iii) calculation accuracy of $0.5 \% / 0.5{ }^{\circ} \mathrm{C}$ for $\mathrm{RH}$ and $T_{\mathrm{db}}$, respectively.

\subsection{Parametric studies}

Parametric hygrothermal simulations were conducted to determine the fluctuation of $\varphi(t)$ and the candidate material's capacity for humidity buffering in a series of closed environment scenarios. Each material was parametrically assessed against five pairs of operating limits $\left(\varphi_{\min }-\varphi_{\max }\right)$; i.e., $0.4-0.5$; 0.5-0.6; 0.6-0.7; 0.7-0.8; 0.8-0.9. The initial moisture content, $w$ was set according to the $\varphi_{\text {min }}$ limit at EMC; i.e., $w_{40}, w_{50}, w_{60}$, $w_{70}$, and $w_{80}$. A number of moisture loading cycles, $N$ was set comprising $12 \mathrm{~h}$ moisture generation (at a rate of $3 \mathrm{~g} \mathrm{~h}^{-1}$ ) followed by $12 \mathrm{~h}$ of no moisture generation ( $24 \mathrm{~h}$ total), i.e., 22 cycles in total. The air infiltration rate $\left(0.35 \mathrm{ACH} \mathrm{h}^{-1}\right)$ and $\varphi_{\mathrm{e}}$ were constant, with the latter value determined according to the $\varphi_{\min }$ limit (i.e., $\varphi_{\mathrm{e}}=0.4,0.5,0.6,0.7$, or 0.8 ) and to a constant dry bulb temperature, $T_{\mathrm{db}}=23{ }^{\circ} \mathrm{C}$. The non-visualized component thickness and area/volume ratio, fabric components, and parameters for the numerical model were set as described in Section 2.4. Expanded numerical simulations were then conducted to quantify the operational energy used for dehumidification loads (enthalpy energy) and cooling demand, with the candidate materials assisting a mixed mode AC system. The upper indoor dry bulb temperature set point, $\left(T_{\mathrm{dbi}, \mathrm{U}}\right)$ was set as $T_{\mathrm{dbi}} \geq 25^{\circ} \mathrm{C}$, and the upper indoor air humidity set point $\left(\varphi_{\max }\right)$ was defined for each pair of operating limits $\left(\varphi_{\mathrm{i}} \geq 0.5,0.6,0.7\right.$, $0.8,0.9$ ), as previously described. In order to simulate instantaneous control response, $50 \mathrm{~kg} \mathrm{~h} \mathrm{~h}^{-1}$ of dehumidification capacity and $50 \mathrm{~kW}$ cooling capacity were assumed for the AC system. Once the $\varphi_{\max }$ and $T_{\mathrm{dbi}, \mathrm{U}}$ set points had been achieved, and if any of the operational limits were exceeded, the ratio of dehumidification or cooling demand could be estimated and the relative effect on energy efficiency calculated. This commonly occurred in cases where the moisture loads were always positive, i.e., where no infiltration of air at lower relative moisture content occurred. For each candidate material, the initial value of $w$ was set according to the $\varphi_{\min }$ limit, i.e., EMC at $w_{40}, w_{50}, w_{60}, w_{70}$, and $w_{80}$. A constant air infiltration rate 0.35 $\mathrm{ACH} \mathrm{h}{ }^{-1}$ ) was used, and the moisture load was derived from the resultant outdoor air moisture content at $\varphi_{\mathrm{e}}=0.95$ at $T_{\mathrm{db}}=23$ ${ }^{\circ} \mathrm{C}$. The non-visualized component thickness and area/volume ratio, fabric components, and parameters for the numerical model were set as described in Section 2.4. The initial boundary conditions were, however, set equally for interior operating limits $\left(\varphi_{\min }-\varphi_{\max }\right)$, and $\varphi_{\mathrm{e}}=0.95$ at $T_{\mathrm{db}}=23{ }^{\circ} \mathrm{C}$. The

Table 2 Hygrothermal functional properties for mesoporous silica. *Values taken from ref. 38

\begin{tabular}{lllllll}
\hline Material & $n\left(\mathrm{~m}^{3} \mathrm{~m}^{-3}\right)$ & $\phi_{\text {pore }}(\mathrm{nm})$ & $\rho_{\mathrm{b}}\left(\mathrm{kg} \mathrm{m}^{-3}\right)$ & $C_{\mathrm{p}}\left(\mathrm{J} \mathrm{kg}^{-1} \mathrm{~K}^{-1}\right)$ & $\lambda\left(\mathrm{W} \mathrm{m}^{-1} \mathrm{~K}^{-1}\right)$ & $A\left(\mathrm{~kg} \mathrm{~m}^{-2} \mathrm{~s}^{-0.5}\right)$ \\
\hline MS-8.3* & 0.76 & 8.3 & 618 & 1691 & 0.05 & 0.550
\end{tabular}


numerical model setup was later adjusted to simulate the kinetics of the water vapour uptake by sequentially fluctuating the adsorption/desorption cycle across an arbitrary sixty cycles $(N=60)$. Each material was parametrically assessed using the same RH limits as for the DVS experiments in Section 2.2 (20$30 \% ; 30-50 \%$; and 50-70\%), where the initial $w$ was set accordingly (i.e., EMC at $w_{20}, w_{30}$ and $w_{50}$ ) and $T_{\mathrm{db}}=23{ }^{\circ} \mathrm{C}$. A constant $\mathrm{ACH}=20.37 \mathrm{~h}^{-1}$ and area/volume ratio (0.01) of the non-visualized component were determined. This was to enable scaling between the DVS chamber volume $\left(V_{\mathrm{ch}}=0.0002945 \mathrm{~m}^{3}\right)$ and the numerical model $\left(V=1 \mathrm{~m}^{3}\right)$, assuming an infiltration rate of $100 \mathrm{sccm}\left(0.006 \mathrm{~m}^{3} \mathrm{~h}^{-1}\right)$ and material quantity of $0.02 \mathrm{~g}$. This enabled validation of the numerical model against the DVS experiments.

\section{Results and discussion}

\subsection{Continuous moisture load sensitivity analysis}

Fig. 3 clearly shows three stages of water vapour adsorption as $w$ reaches equilibrium moisture content (EMC), where each stage was identified within a specific portion of the isotherm as depicted in Fig. 2a. The first stage (schematically sketched in Fig. 2b) between points $a$ and $b$ represents an early saturation stage of the materials in the first $48 \mathrm{~h}$ where a steep $\varphi$ gradient was found. In the cases of MIL-101, ${ }^{66} \mathrm{PS}-\mathrm{C} 16-\mathrm{R}^{67}$ and SBA-15, the higher $\Delta w$ gradient during adsorption between $\varphi=0$ to $c a$. 0.4, and desorption between 0 to ca. 0.9 resulted in a less pronounced curve and a small but significant delay when achieving the 1st inflection point $b$. A second stage was a subplateau between point $b$ and $c$ where a characteristic stabilized $\varphi_{\mathrm{i}}$ corresponded to the highest $\Delta w$ at the 2 nd inflection point $c$, i.e., the percolation threshold. The slope of the sub-plateau indicates its dependency upon the steepness of the $w: p_{\mathrm{v}} / p_{0}$ gradient corresponding to maximum pore volume. Previous work has demonstrated that the positive correlation between the moisture storage capacity $(\Delta w)$ and the optimum $\varphi$ operating range for a given isotherm can also be identified. ${ }^{56}$ Almost all samples exhibited the sub-plateau segment in their isotherms, which started from point $b$ (onset of multilayer physisorption between $\varphi=c a$. 0.35-0.90), with the exception of the aerogel. ${ }^{68}$ This suggests a prolonged capillary conduction stage. In the third stage between points $c$ and $d$, a rapid increase in $\varphi_{\mathrm{i}}$ was observed with noticeable variation towards $\mathrm{EMC}_{100}$, especially in materials having type V isotherms (e.g., KIT-1 (ref. 69)). The progressive reduction in pore volume strongly affected the time taken to reach inflection point $d$ towards $\mathrm{EMC}_{100}$, as a consequence of the low $\Delta w$ on that portion of the isotherm. Evidence of this was found for MCM-41@180, ${ }^{56}$ which was the first to achieve $\mathrm{EMC}_{100}(112 \mathrm{~h})$ and has the lowest pore volume $\left(0.53 \mathrm{~g} \mathrm{~cm}^{-3}\right)$. However, it was apparent that by having a greater $\Delta w$ between points $c$ and $d$, the elapsed time before reaching $\mathrm{EMC}_{100}$ was significantly increased. Evidence of this was found when comparing KIT-1 (152 h) and FSM-16 (168 h), ${ }^{69}$ both with similar $\Delta w$ at point $c\left(460 \mathrm{~kg} \mathrm{~m}^{-3}\right)$, but with the latter having a steep $w: p_{\mathrm{v}} / p_{0}$ gradient resulting in a higher $\Delta w$ above $\varphi=0.7$ $\left(\sim 44 \mathrm{~kg} \mathrm{~m}^{-3}\right)$.

\subsection{Water vapour exchange performance}

Fig. 4 shows the cumulative water vapour uptake for all candidate materials. The same correlations were observed in Section 3.1 for stage 1-3 water vapour adsorption and the corresponding portions of the isotherm (see Fig. 2). It appears that in the first stage (points $a$ and $b$ ) there is an 'apparent' high initial

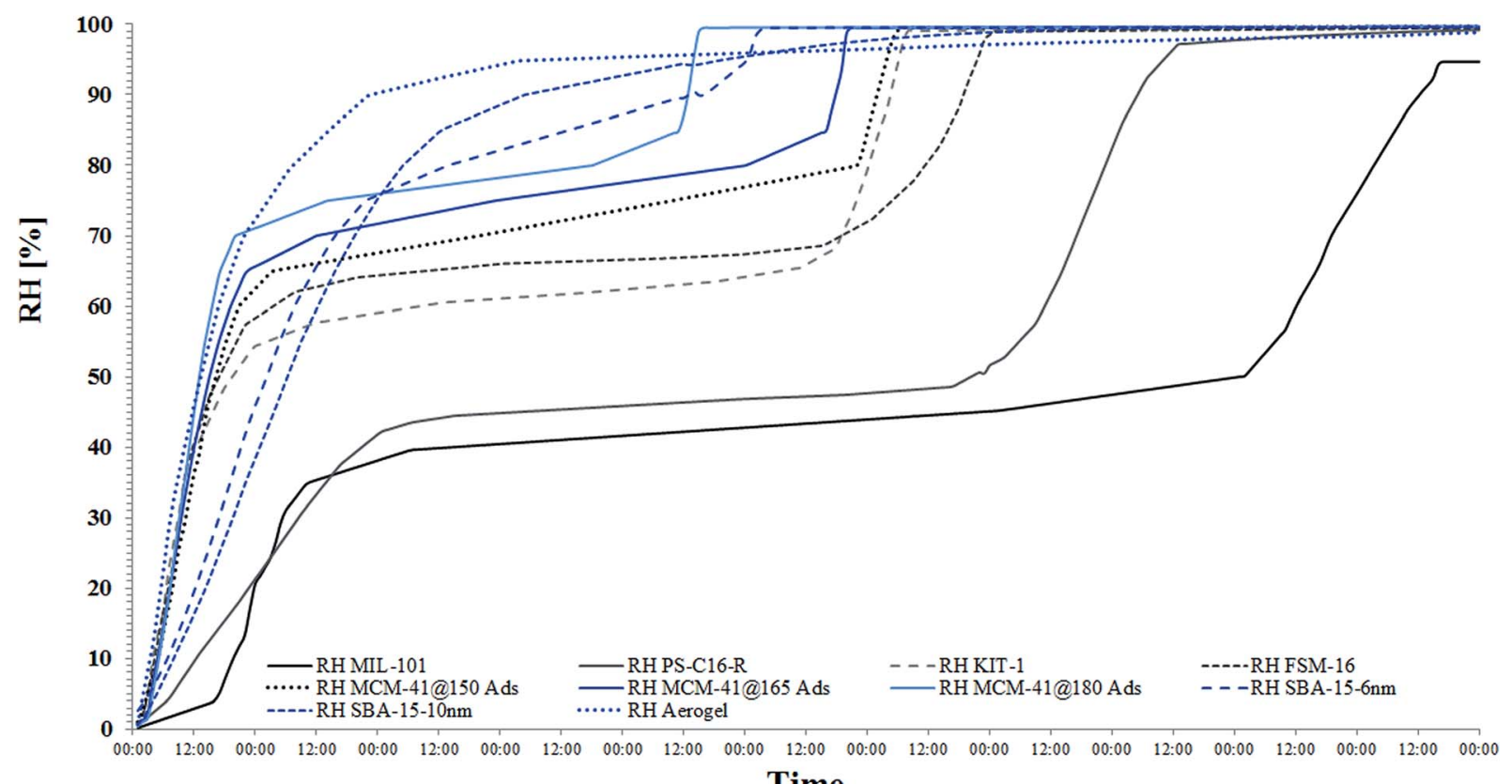

Time

Fig. 3 Water vapour sorption kinetic stages for all desiccant candidates when achieving $\mathrm{EMC}_{100}$. Initial $w=0$ for all desiccant materials and the moisture load applied is the moisture content of the infiltrated air at $\mathrm{ACH}=0.35^{-1}$, where $\varphi_{\mathrm{e}}=0.95$. 


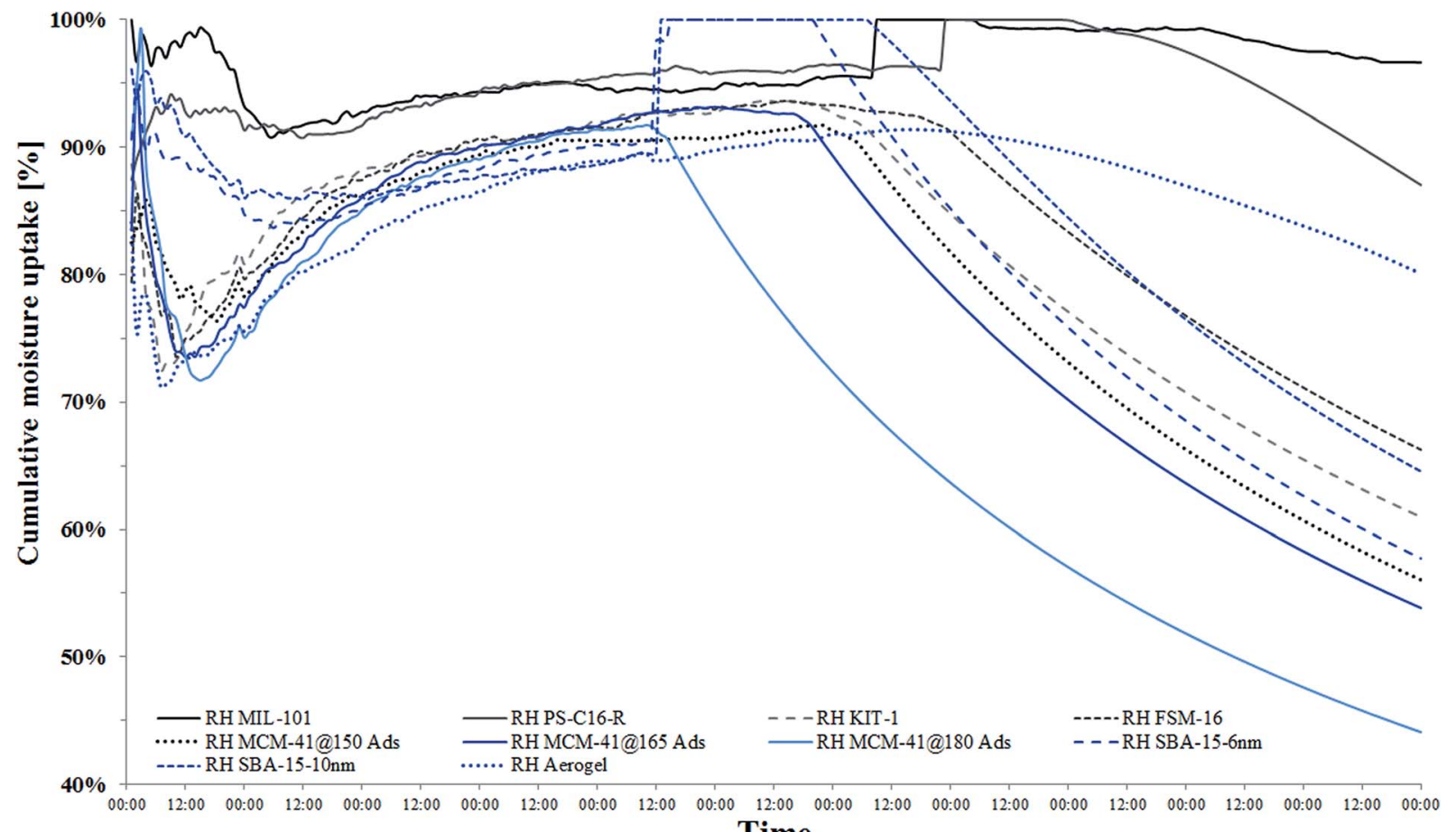

Fig. 4 Cumulative water vapour uptake for all desiccant candidates. Initial $w=0$ for all desiccant materials and the moisture load applied is the moisture content of the infiltrated air at $\mathrm{ACH}=0.35^{-1}$, where $\varphi_{\mathrm{e}}=0.95$.

water vapour uptake (relative to $w=0$ ) followed by a visible depression caused by early saturation. This applied to MCM-41, KIT-1, FSM-16, and aerogel. Note that in the cases of MIL-101, PS-C16-R and SBA-15 the cumulative water vapour adsorption was clearly higher (between $84 \%$ to $99 \%$ ) and controlled by the higher initial $\Delta w$ gradient between points $a$ and $b$ (see Fig. 2a). After this stage, a sub-plateau was observed in the second stage (points $b$ and $c$, with the highest $\Delta w$ gradient), which corresponded to maximum pore volume. Here some materials (MIL101, PS-C16-R and SBA-15) reached $100 \%$ of the cumulative water vapour uptake. Once point $c$ of the isotherm was reached the moisture content (with respect to pore volume) was sufficiently high for performance to begin to decay after successive internal moisture load cycles. This indicates moisture content
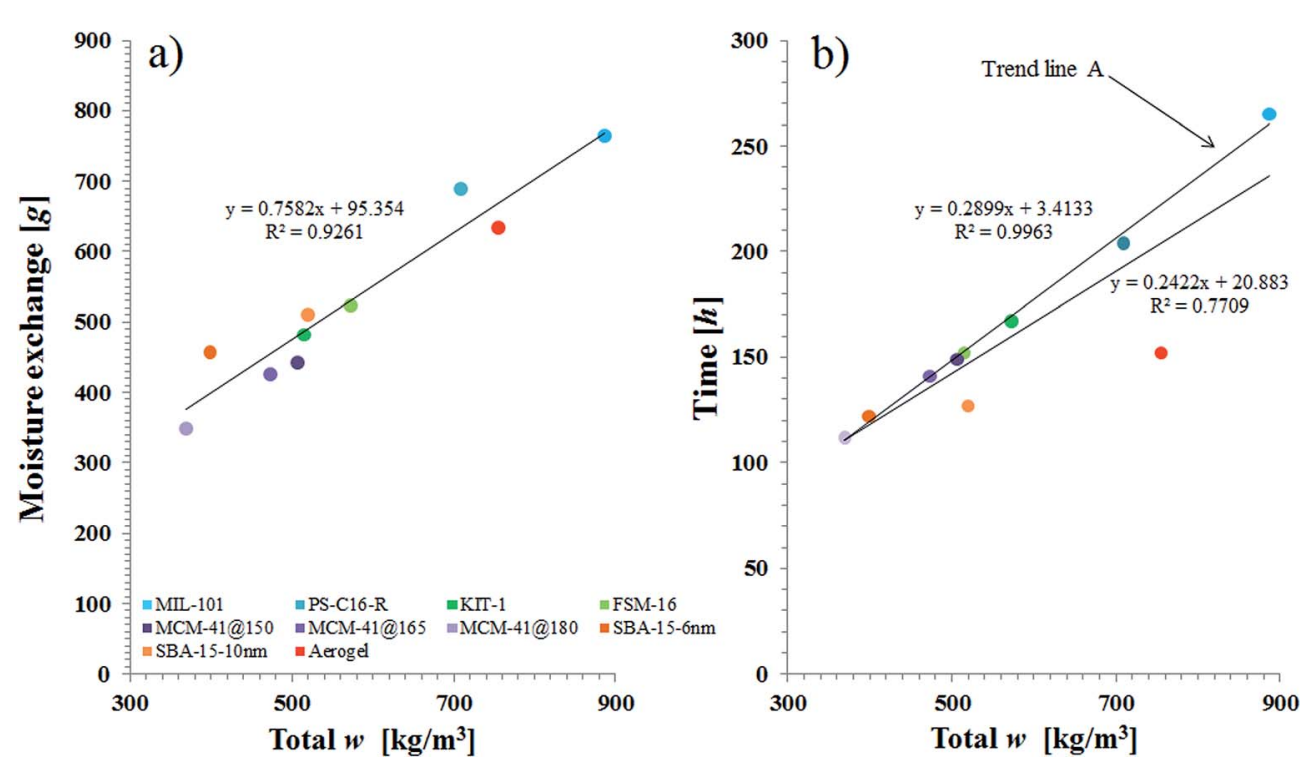

Fig. 5 (a) Linear correlation between the moisture storage capacity, $w$ and the water vapour being exchanged. (b) Relationship between total moisture storage capacity and time taken to achieve $\mathrm{EMC}_{100}$. 
dependency and reduced water vapour adsorption ability prior to reaching $w_{100}$ from point $c$ of the isotherm. Fig. 5a shows a positive linear correlation between the moisture storage capacity, $w$ and the water vapour being exchanged (against time) with the absorbent. However, Fig. 5b shows that the relationship between $w$ and the time taken to exceed the $\varphi_{\max } \operatorname{limit}(\varphi=$ $0.95)$ correlates more strongly with type $\mathrm{V}$ isotherms $\left(R^{2}=0.99\right)$ compared with type III isotherms $\left(R^{2}=0.77\right)$. This could partially be explained by the observation that the process of water vapour adsorption was triggered early by a capillary condensation stage on type III isotherms. Therefore, SBA-15 10 $\mathrm{nm}$ and aerogel material do not fit trend line A since their capillary potential and capacity for water vapour adsorption are already lowered.

\subsection{Water vapour buffering simulations}

Fig. $6 \mathrm{a}$ and $\mathrm{b}$ shows the $\mathrm{RH}$ buffering results for repeated longterm loop cycling (at $N=12$ ) of all material candidates. The operating range $\left(\varphi_{\min }-\varphi_{\max }\right)$ of each test was $0.4-0.5$ and $0.7-$ 0.8 , respectively. The absence of water vapour buffering can be seen followed by an early decay process which correlates to the first stage of water vapour adsorption between points $a$ and $b$ of the isotherm (Fig. 2a). This sudden decay relates to the smaller $\Delta w$ gradient seen in Fig. 7a, causing the material to fail after $N$ number of cycles when the fluctuation of $\varphi(t)$ exceeds the $\varphi_{\max }$ limit (Fig. 7b). From Fig. 7b it is apparent that the progressive decay until material failure corresponds with the largest proportion of water vapour adsorption (see Fig. 7a) in each operating range. The most suitable candidate materials for each range can be identified as that with the longest time before exceeding the $\varphi_{\max }$ limit. This suggests that the sub-plateau segment (see $y$-axis displacement in Fig. 3 ) is sensitive both to $x$ axis adjustments in the sorption isotherm (i.e., pore size distribution) and to the value of $\Delta w$ ( $w: p_{v} / p_{0}$ gradient) between $\varphi_{\mathrm{i}, \mathrm{L}}-\varphi_{\mathrm{i}, \mathrm{U}}$ limits.

\subsection{Air dehumidification and energy consumption}

Fig. $8 \mathrm{a}-\mathrm{c}$ show the ratio of dehumidification loads removed by the materials once they achieve the $\varphi_{\max }$ set point on the mixed mode AC system (repeated for ranges between: 40-50; 60-70;
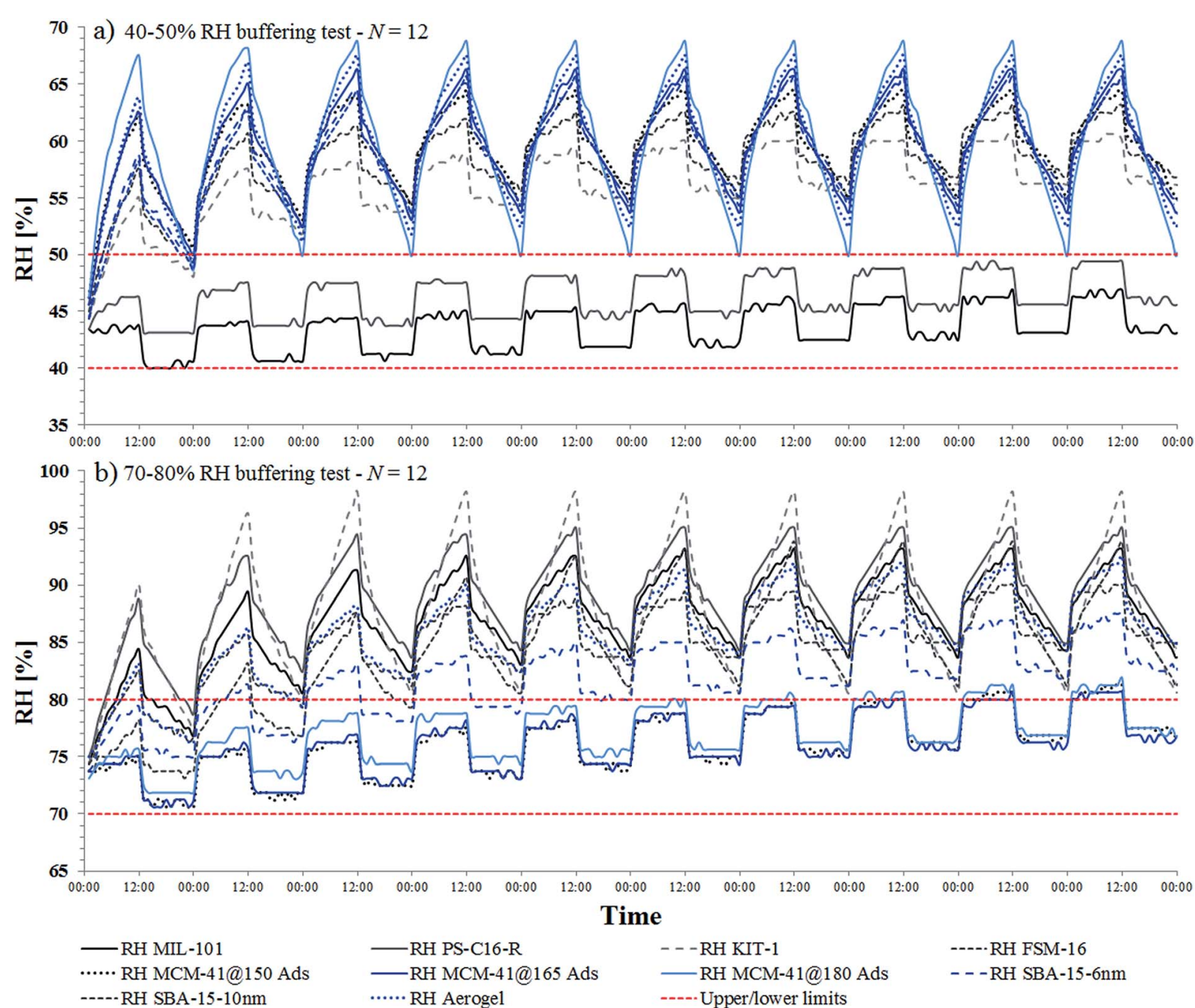

Fig. $6 \mathrm{RH}$ buffering results for all desiccant candidates, where the number of cycles, $N=12$. (a) Shows the simulations results for RH buffering between $40-50 \%$, and (b) $70-80 \%$ operating ranges. The red-dotted lines correspond to the maximum and minimum $\mathrm{RH}$ limits. 
and $70-80 \% \mathrm{RH})$. The steepness of the curve was found to be dependent on the time required to achieve the corresponding EMC (e.g., $\mathrm{EMC}_{50}$ as seen in Fig. 8a). This supports the idea that total control $(100 \%)$ from the AC system corresponds to the lower $\Delta w$ gradient, whereas a plateau (at $0 \%$ ) means that the indoor moisture load was fully regulated by the desiccant by having a higher $\Delta w$ gradient. In all cases, it can be recognized that a higher elapsed time before the inflection of the curve start there is a corresponding material that fits within the optimum operating ranges; for example, MIL-101 and PS-C16-R $(\varphi=0.4-$ 0.5), MCM-41@150, ${ }^{56}$ KIT-1, and FSM-16 ( $\left.\varphi=0.6-0.7\right)$, and all MCM-41 types $(\varphi=0.7-0.8)$. Once the inflection point starts (above 0\%; see red circles in Fig. 8a) in the sub-plateau region, the adsorbent progressively has lower potential to fully regulate $\varphi_{\mathrm{i}}$ and air dehumidification starts to operate.

Fig. 9 shows a significant difference between the resultant indoor $\mathrm{RH}(t)$ and the material's $\mathrm{RH}(t)$ in all simulations. Since the adsorbent appears not to have achieved EMC (i.e., $\mathrm{EMC}_{50-70-80}$ ) a distinctive offset between both curves was observed. This suggests that the material may continue adsorbing water vapour whilst the $\varphi_{\text {min }}$ set point on the AC is still dehumidifying the indoor air, and hence working in true mixed mode.

Fig. 10 shows a positive linear correlation between the moisture sorption capacity ( $\Delta w$ gradient) and the latent heat used for air dehumidification for each specific operational range. This satisfactorily proves that passive regulation of $\mathrm{RH}$ fluctuations in a specific closed environment can fully be controlled by materials where a higher $\Delta w$ gradient is found whilst consuming less energy. This was previously evidenced in Fig. $8 \mathrm{a}-\mathrm{c}$, where reduction of the dehumidification loads removed by the AC system was strongly related to a higher $\Delta w$ gradient corresponding to materials that fit within the optimum operating ranges. Consistent agreement was also observed between the decay (up to material failure) and the latent heat of dehumidification, wherein the most suitable candidate materials can be identified in Fig. 7b. A significant increment in the resultant indoor air temperature was observed in some cases (e.g., MIL-101 and PS-C16-R), most likely due to heat of adsorption. As a result, an extra cooling load was added to both MIL-101 and PS-C16-R (i.e., 0.22 and $0.16 \mathrm{KW}$ respectively) in order to maintain isothermal conditions $\left(T_{\mathrm{dbi}}=23{ }^{\circ} \mathrm{C}\right)$. Fig. 11 shows the total energy used for air dehumidification (latent heat) and the energy used for cooling purposes (Fig. 11a), and no correlation trend $\left(R^{2}=0.2706\right)$ between total moisture storage, $w$ and total latent heat for air dehumidification (Fig. 11b). In the latter case, it can be seen that having higher $w$ (e.g. aerogel, MIL-101, PS-C16-R and SBA-15 $10 \mathrm{~nm}$ ) does not result in lowering the energy used for dehumidification purposes when assuming total pore volume capacity. Evidence of this can be seen when comparing the total latent heat used for type V and type III isotherms; e.g., MCM-41@180 (1.51 kW and $\left.w=369.4 \mathrm{~kg} \mathrm{~m}^{-3}\right)$ and aerogel $(1.65 \mathrm{~kW}$ and $w=754.8 \mathrm{~kg}$ $\mathrm{m}^{-3}$ ), with the latter having $w \sim 2$ times higher compared to MCM-41@180. These results provide evidence for the premise in which adsorbents are expected to fully operate under total adsorption capacity, independent of isotherm shape, rather than for specific applications and $p_{\mathrm{v}} / p_{0}$ scenarios.

\subsection{Experimental work and model validation}

Fig. 12 compares the experimental DVS and numerical simulations (water vapour sorption/desorption kinetics) for the three newly synthesised materials (MCM-41@165, SBA-15 $6 \mathrm{~nm}$ and SBA-15 $10 \mathrm{~nm}$ ). The upper and lower \% RH buffering limits were defined as 20-30\% RH; 30-50\% RH; and 50-70\% RH in Fig. 12. Experimentally, it appears that for all materials EMC (red dotted line in Fig. 12) was achieved at $N=3$ for cases where the $\Delta w$ gradient was sufficiently small (a, b, d, e, and g) with respect to
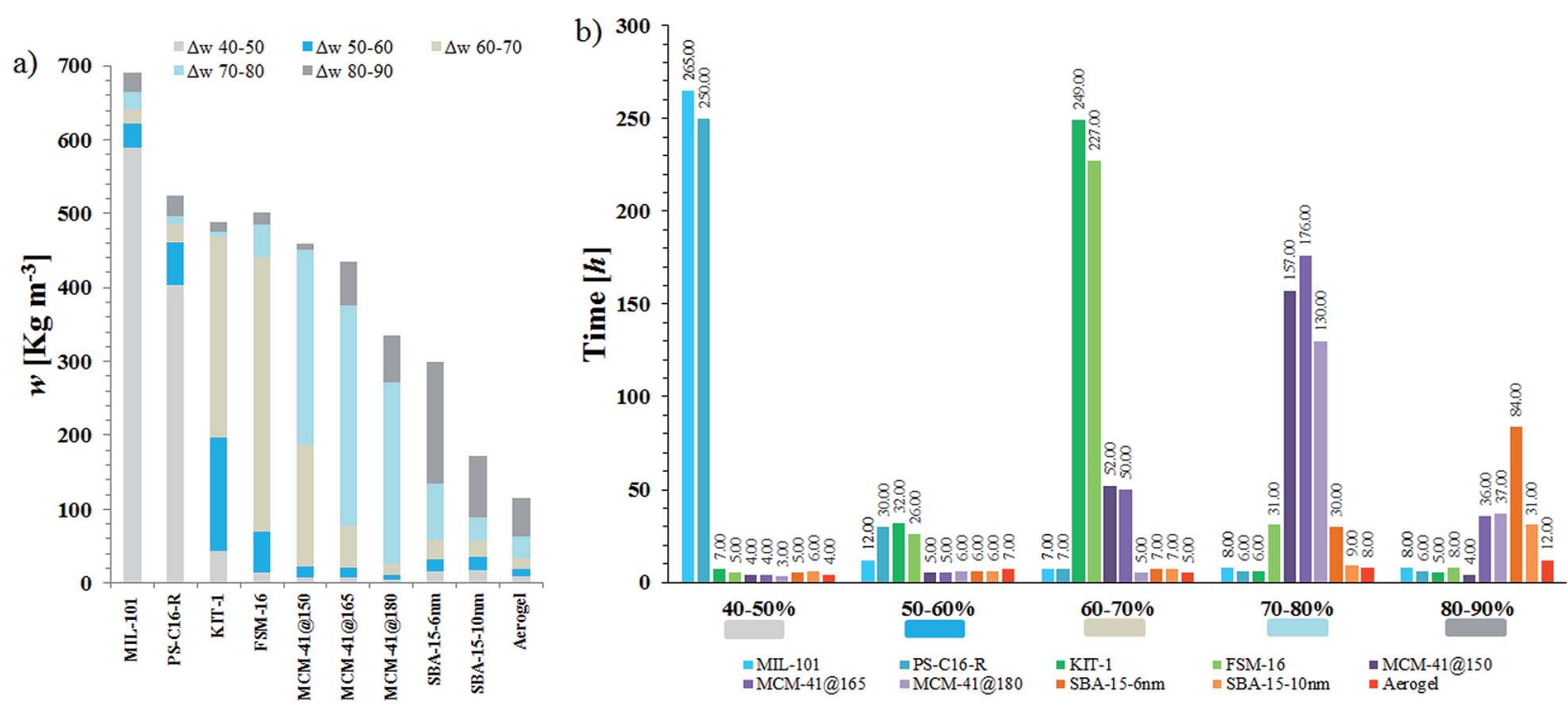

Fig. 7 (a) Water vapour uptake capacity at different $\Delta w$ for all desiccant candidates $(\Delta w=40-50 ; 50-60 ; 60-70 ; 70-80$; and $80-90)$. (b) Time taken for all desiccant materials when the fluctuation of $\varphi(t)$ exceeds the $\varphi_{\max }$ limit; where $\Delta w=40-50 ; 50-60 ; 60-70 ; 70-80 ;$ and $80-90$. This also correspond to the threshold when the materials reaches failure at the number of cycles, $N=60$. 


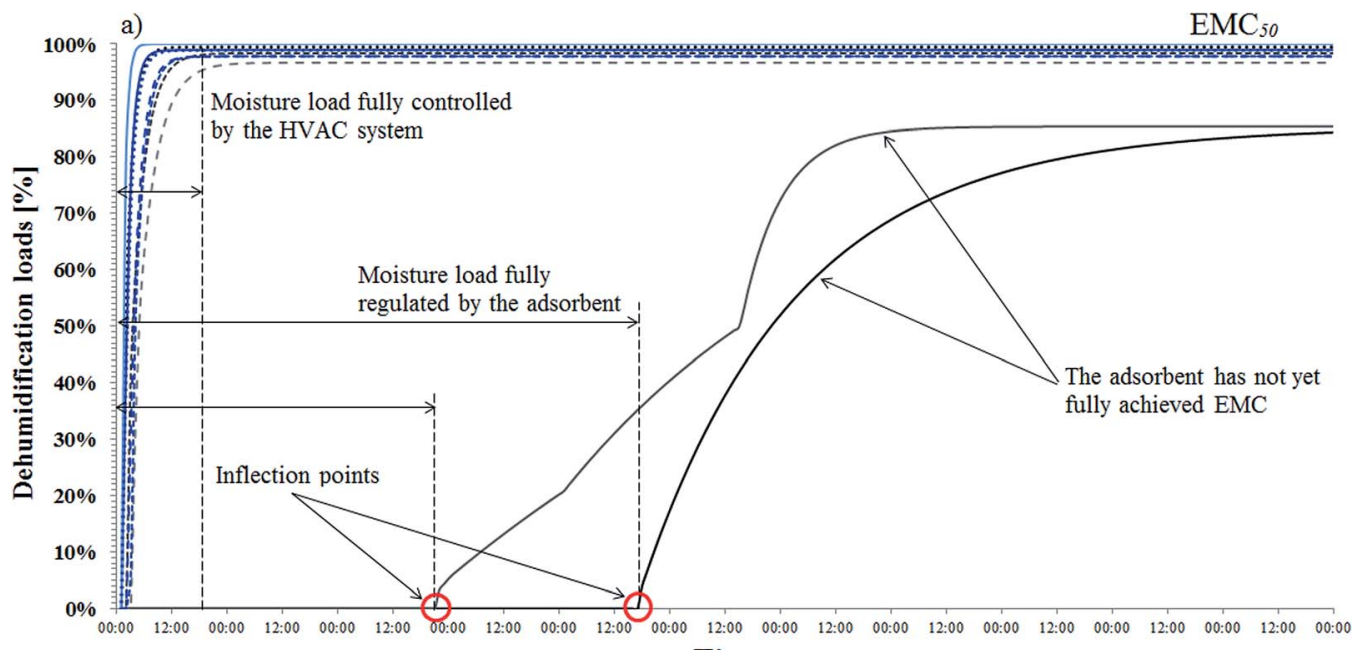

b)

Time

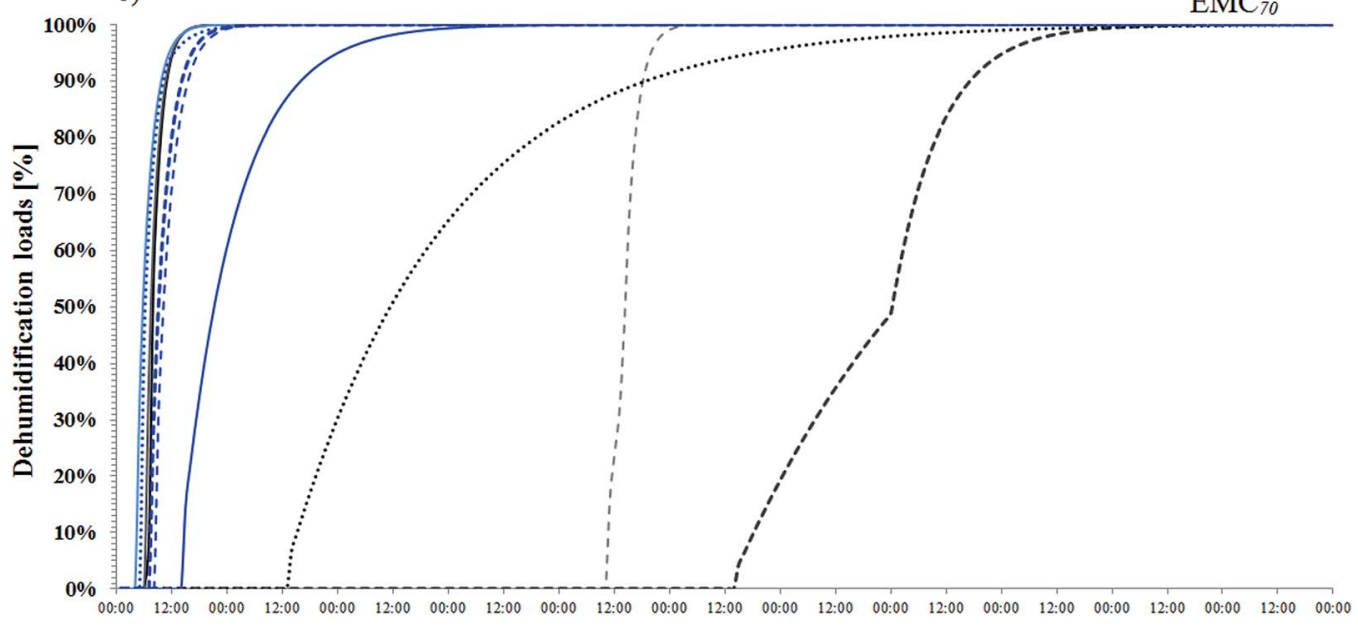

c)

Time

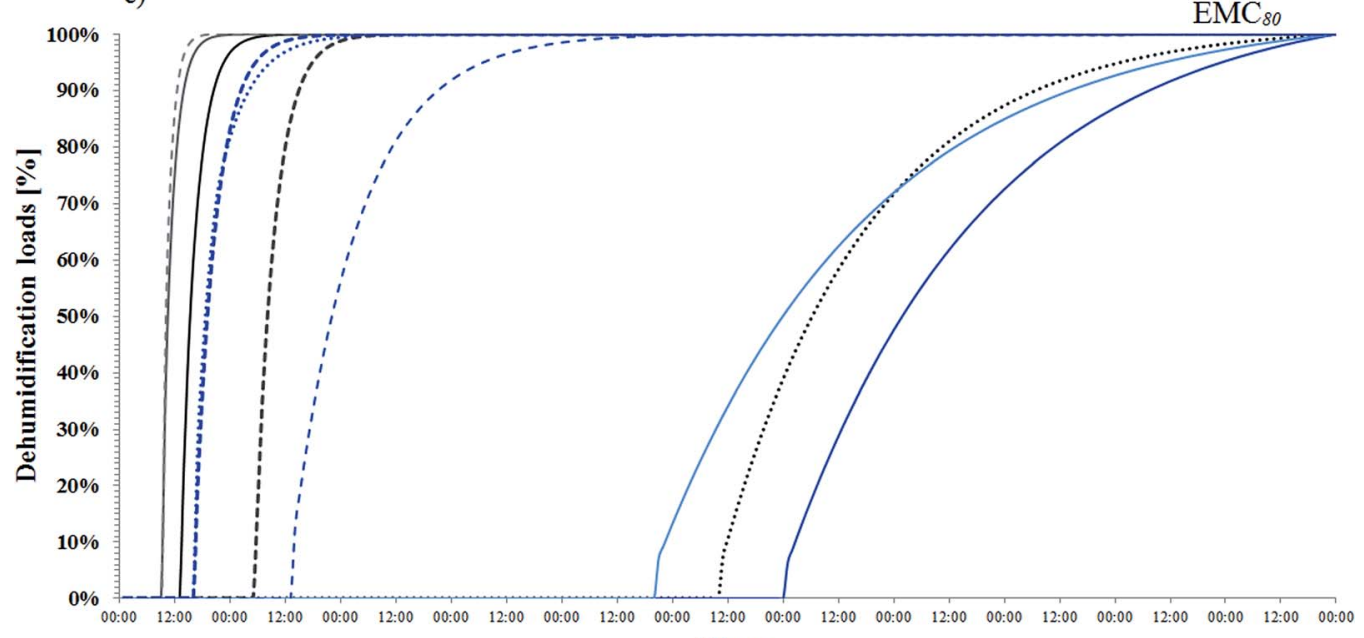

Time

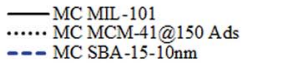

…..MC MCM-11@150

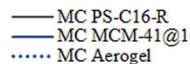
…. MC Aerogel

Fig. 8 Dehumidification ratio performed by the AC system and the desiccant candidates according to the operating ranges (a) 40-50; (b) 60-70; and (c) $70-80 \% \mathrm{RH}$. Here, $0 \%$ indicates that the desiccant candidate is fully regulating indoor $\mathrm{RH}$. Above $0 \%$ indicates that the $\mathrm{AC}$ system start to working in truly mixed mode. The time taken for reaching EMC at the corresponding operating ranges are solely dependent upon the $\Delta w$ gradient. 


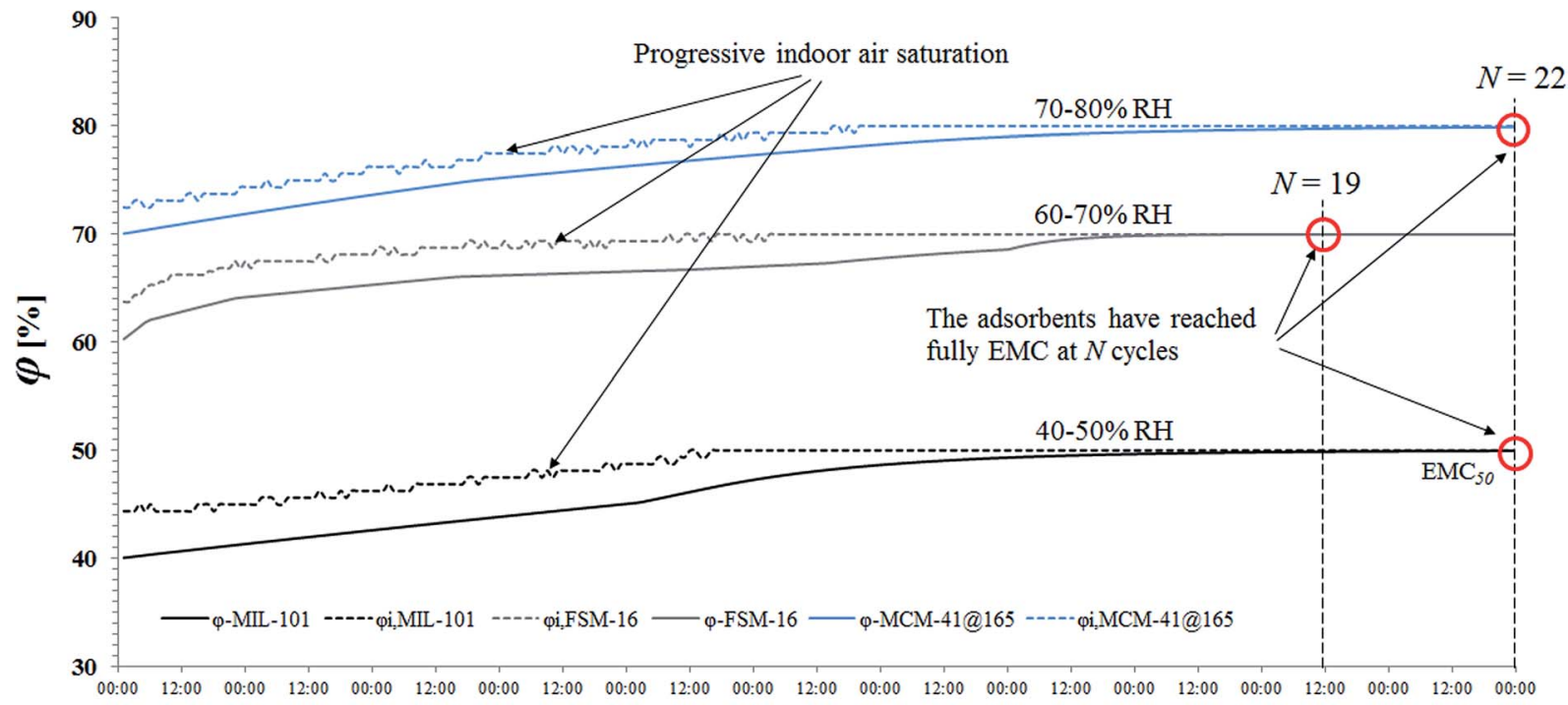

Time

Fig. 9 Comparison between the resultant indoor $\mathrm{RH}(t)$ and the material's $\mathrm{RH}(t)$ at different operating ranges for desiccant materials $\mathrm{MIL}-101$, FSM-16 and MCM-41@165. The offset dotted-lines represent the progressive indoor air saturation towards equilibrium with the desiccant at the respective $\mathrm{ACH}^{-1}$. The total number of cycles, $\mathrm{N}=22$ and the red circles represents when the desiccants have been reached $\mathrm{EMC}$ at the corresponding operating $\mathrm{RH}$ ranges.

the relevant portion of each sorption isotherm (see Fig. 1). Additionally, it appears that the kinetics for sorption/desorption within the $\%$ RH buffering limits was highly sensitive to the $\Delta w$ gradient. This corresponded to a rapid response (steep adsorption/desorption curve) for the smallest $\Delta w$ gradient. Evidence of this was found in MCM-41@165 operating at 20-30 and $30-50 \%$ RH (see red boxes in Table 3). In all other cases it was evidenced by a less steep sorption/desorption curve and corresponding to those with a higher $\Delta w$ gradient. To some extent, the numerical predictions seen in Fig. 12(a, b, d, e, and g) appear to be slightly underestimated (solid black line) towards the time in achieving EMC, especially in those between $\Delta w_{20-50}$ (see Table 3). This is normally found in numerical models due to the lack of a dynamic input for $w$, with respect to

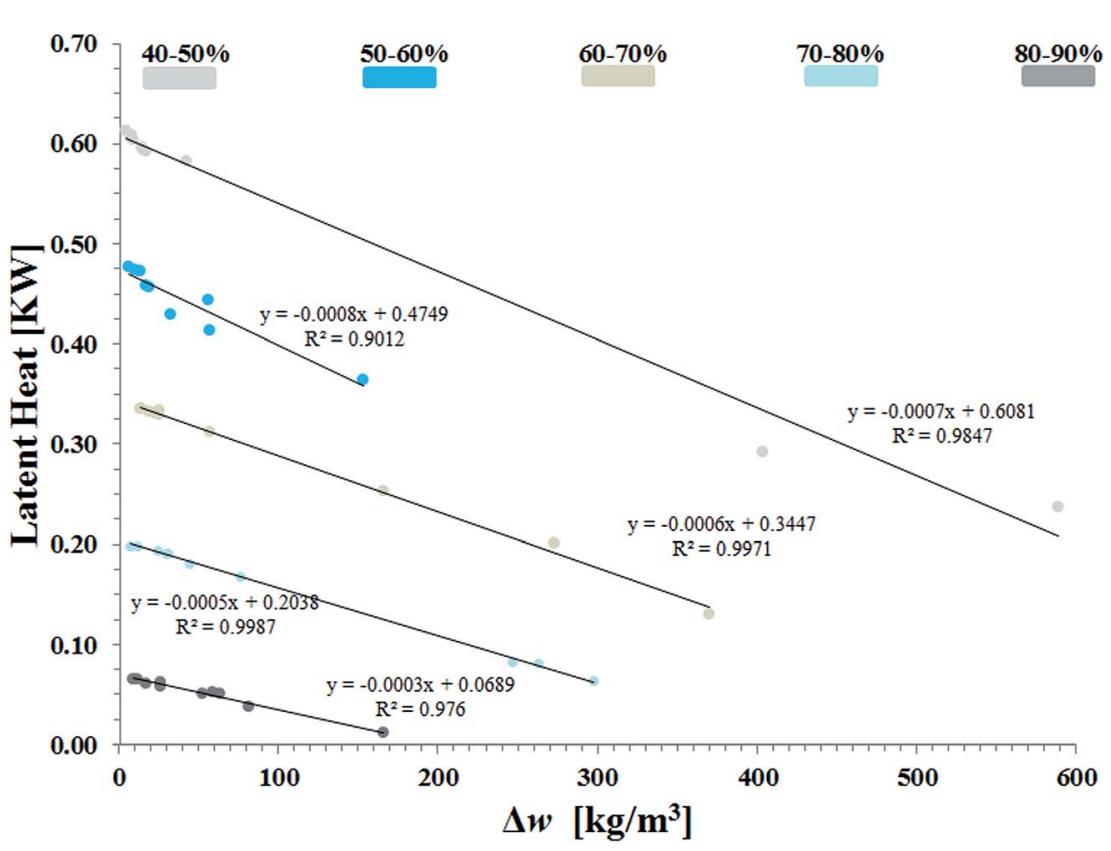

Fig. 10 Correlation between moisture sorption capacity and the latent heat used for air dehumidification from the AC system at the corresponding operating ranges (40-50\%; 50-60\%; 60-70\%; 70-80\%; 80-90\%). Each trend line correspond to the aggrupation of all desiccant candidates when performing the air dehumidification through the AC system. 

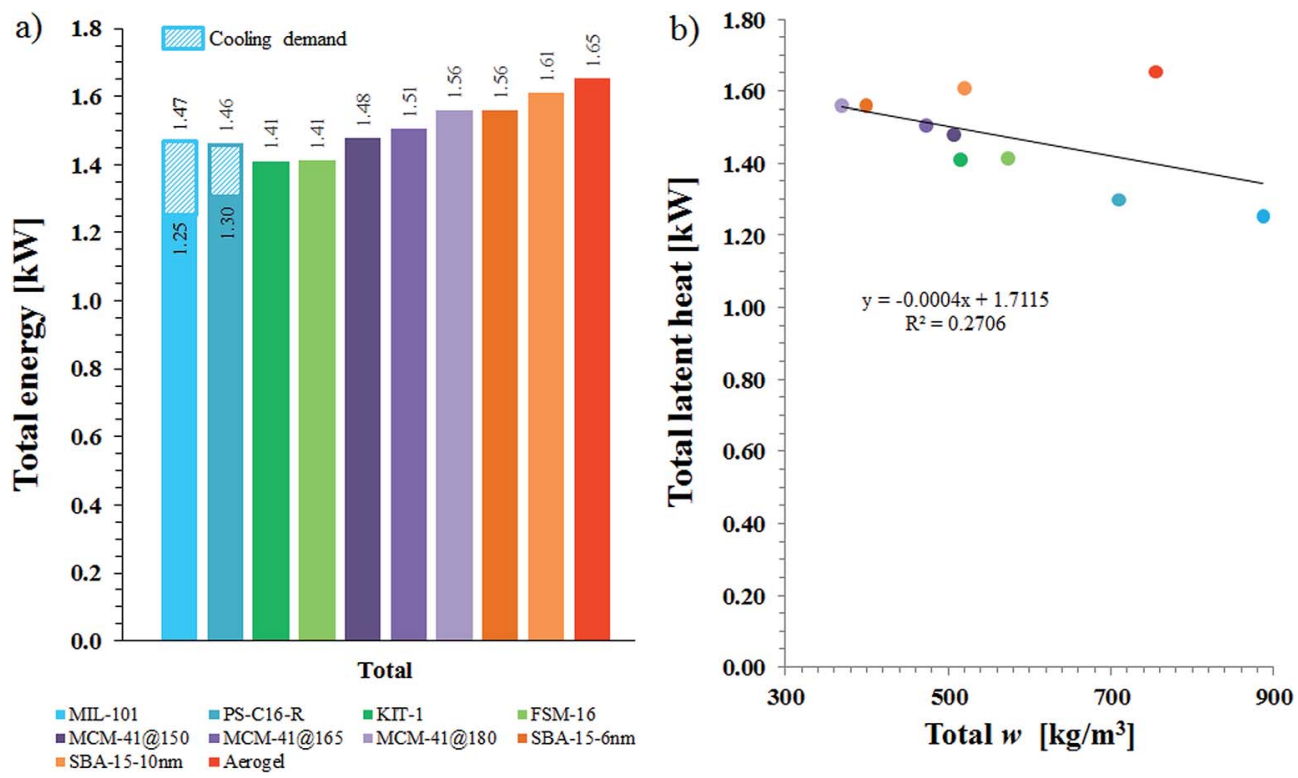

Fig. 11 (a) Total energy used for air dehumidification for all desiccant candidates. In the case of materials MIL-101 and PS-C16-R, a cooling demand is represented by the hatched box above the values. (b) Non-linear correlation between total moisture storage, $w$ and total latent heat for air dehumidification. Type III isotherms can clearly be recognized as the precursors of this non-linear trend as their total moisture content, $W$ do not correlate with the total energy used for air dehumidification and cooling loads, resulting in $R^{2}=0.2706$.

the time-response for water vapour adsorption at partial EMC; i.e., $w$ inputs are assumed to be at full EMC for single sorption isotherms. Further analysis confirmed that the average difference (\%) between experimental and numerical $w$ data for all sorption cycles was significantly attributed to this; e.g., MCM41@165 with $43.4 \%$ within the $\Delta w_{30-50}$ cycle seen in Table 4 . In the case of those having greater $w$ between the upper and lower
\% RH buffering limits (c, f, h, and i from Fig. 12), it is suggested that for both experimental and numerical data, their capacity for water vapour adsorption is significantly beyond the required time period for achieving EMC (see Table 3). Besides, for all candidates seen in red circles (Fig. 12), there appears to be a combination of time-response together with a hysteresis phenomenon. The latter, can be recognized by the highest

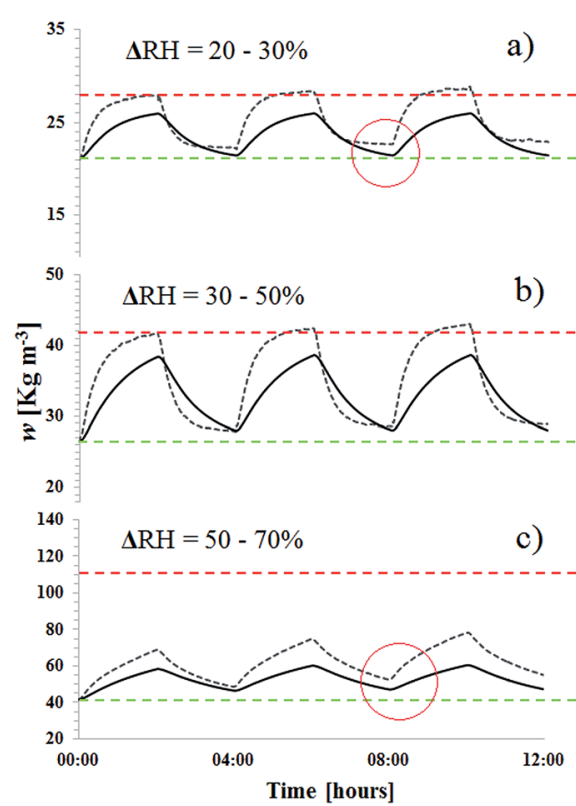

----MCM-41@165 Physical —MCM-41@165 wUFI
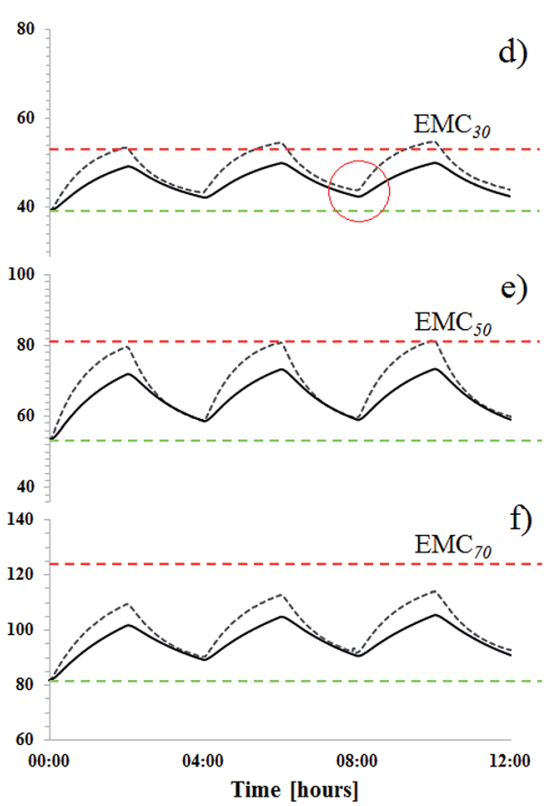

----SBA-15 $6 \mathrm{~nm}$ Physical —-SBA-15 $6 \mathrm{~nm}$ WUFI

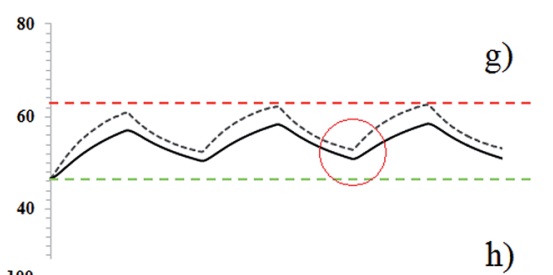

100

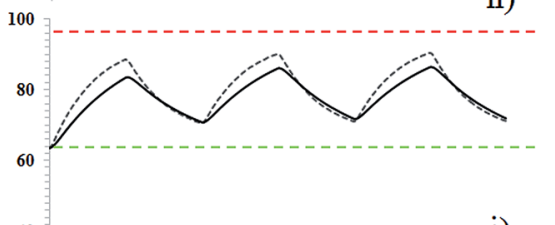

i)

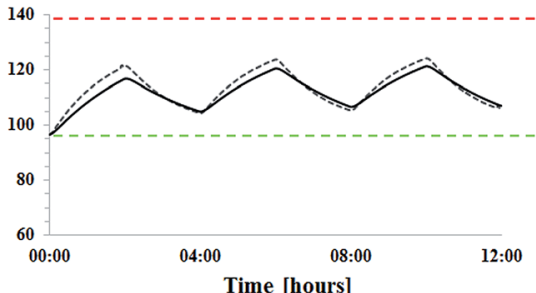

----SBA-15 $10 \mathrm{~nm}$ Physical — SBA-15 $10 \mathrm{~nm}$ WUFI

Fig. 12 Water vapour sorption/desorption kinetics comparison between experimental DVS and numerical simulations. The results are deemed to be read horizontally, where (A) indicates the operating range $\Delta \mathrm{RH}=20-30 \%$; (B) $\Delta \mathrm{RH}=30-50 \%$; and $(\mathrm{C}) \Delta \mathrm{RH}=50-70 \%$. The red-dotted lines indicate achieving the corresponding EMC, whereas the green-dotted lines indicate the base line for the initial $W$. 
Table 3 Moisture storage capacity at different $\Delta w$ for all new desiccant materials. The time in achieving EMC is also presented with an approximate time (h) for each desiccant at the corresponding ranges: $\Delta w_{20-30} ; \Delta W_{30-50} ;$ and $\Delta w_{50-70}$. These time values represent numerical predictions based on $w$ inputs that are assumed to be at full EMC

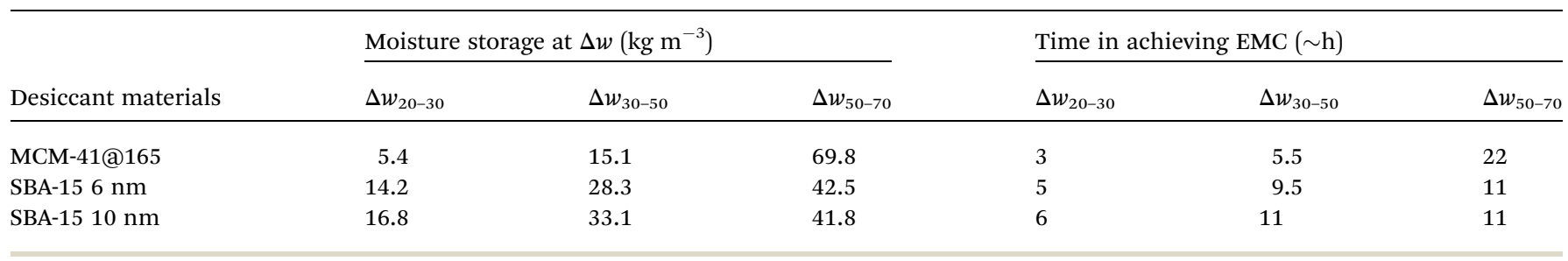

Table 4 Average difference (\%) between experimental and numerical $w$ data for all new mesoporous desiccant materials, when modelling for each independent $\mathrm{RH}$ buffering scenario $20-30 \% \mathrm{RH} ; 30-50 \% \mathrm{RH}$; and $50-70 \% \mathrm{RH}$. The $w$ differences are provided for the following ranges: $\Delta w_{20-30} ; \Delta w_{30-50}$; and $\Delta w_{50-70}$, denoted with the vowels (a-i) according to Fig. 12, and for the three completed adsorption/desorption cycles

\begin{tabular}{|c|c|c|c|c|c|c|c|c|c|}
\hline \multirow[b]{4}{*}{ Cycles } & \multicolumn{9}{|c|}{ Mesoporous desiccant materials } \\
\hline & \multicolumn{3}{|c|}{ MCM-41@165 } & \multicolumn{3}{|c|}{ SBA-15 $6 \mathrm{~nm}$} & \multicolumn{3}{|c|}{ SBA-15 $10 \mathrm{~nm}$} \\
\hline & $\Delta w_{20-30}$ & $\Delta w_{30-50}$ & $\Delta w_{50-70}$ & $\Delta w_{20-30}$ & $\Delta w_{30-50}$ & $\Delta w_{50-70}$ & $\Delta w_{20-30}$ & $\Delta w_{30-50}$ & $\Delta w_{50-70}$ \\
\hline & $\mathrm{a}$ & $\mathrm{b}$ & $\mathrm{c}$ & $\mathrm{d}$ & $\mathrm{e}$ & $\mathrm{f}$ & $\mathrm{g}$ & $\mathrm{h}$ & i \\
\hline Ads. cycle 1 & $44.4 \%$ & $43.3 \%$ & $48.4 \%$ & $44.4 \%$ & $43.6 \%$ & $39.8 \%$ & $40.0 \%$ & $35.2 \%$ & $27.8 \%$ \\
\hline Des. cycle 1 & $11.3 \%$ & $-56.6 \%$ & $28.2 \%$ & $16.9 \%$ & $6.5 \%$ & $13.0 \%$ & $24.9 \%$ & $1.7 \%$ & $3.0 \%$ \\
\hline Ads. cycle 2 & $48.8 \%$ & $40.5 \%$ & $45.9 \%$ & $38.2 \%$ & $32.2 \%$ & $28.6 \%$ & $33.1 \%$ & $18.5 \%$ & $11.5 \%$ \\
\hline Des. cycle 2 & $29.4 \%$ & $-27.9 \%$ & $41.8 \%$ & $21.3 \%$ & $7.3 \%$ & $12.0 \%$ & $23.2 \%$ & $-3.7 \%$ & $-4.2 \%$ \\
\hline Ads. cycle 3 & $51.8 \%$ & $43.4 \%$ & $52.4 \%$ & $38.1 \%$ & $33.4 \%$ & $29.0 \%$ & $32.7 \%$ & $16.6 \%$ & $7.6 \%$ \\
\hline Des. cycle 3 & $36.3 \%$ & $-15.0 \%$ & $49.2 \%$ & $23.9 \%$ & $11.0 \%$ & $14.8 \%$ & $24.1 \%$ & $-3.7 \%$ & $-4.6 \%$ \\
\hline
\end{tabular}

average (\%) values at the end of the third cycle shown in Table 4 (see a, c, d, and g). In both adsorption and desorption cycles, this could be largely due to the presence of scanning curves within the hysteresis loop. However, the corresponding loops at this stage are unidentified. Conversely, there is close agreement (full sorption/desorption reversibility) when a smaller $\Delta w$ gradient is found; for example, SBA-15 $10 \mathrm{~nm}$ operating in the $50-70 \%$ RH ranges (see Fig. 12i). This could be explained because SBA-15 $10 \mathrm{~nm}$ showed the lowest average difference between experimental and numerical $w$ data (see Table 4 $7.6 \%$ ), which indicates a high degree of sorption/desorption reversibility (and small hysteresis $-4.6 \%$ ). On the other hand, numerical data of the final EMC were accurately predicted (refer to Section 3.1), suggesting that there is some level of variance between short and long periods for water vapour adsorption/ desorption kinetics. This perhaps indicates a need for further research in which the concept of time-response for water vapour adsorption, hysteresis loops and the associated scanning curves can be fully implemented by the current state-of-the-art hygrothermal numerical models.

\section{Conclusions}

Three new mesoporous desiccant materials (MCM-41@165, SBA-15 $6 \mathrm{~nm}$ and SBA-15 $10 \mathrm{~nm}$ ) were successfully synthesised with pore size modulation, in order to experimentally recreate the ideal isotherms determined (for differing applications) by the hygrothermal model optimization technique previously developed by the authors. A series of numerical simulations were performed to assess the desiccants' capacity for regulating indoor RH and the corresponding impact on energy efficiency when assisting a mixed mode AC system. The simulated results clearly showed three stages of water vapour adsorption that strongly related to the $\Delta w$ gradient showing a positive linear correlation with the latent heat used for air dehumidification. The results were also consistent with the predictions for progressive decay and the point of failure, indicating the suitability of the materials for the $p_{\mathrm{v}} / p_{0}$ scenarios for which they had been designed. Increasing $w$ did not result in lowering the energy used for dehumidification purposes, especially for the type III isotherm materials, and found no correlation $\left(R^{2}=\right.$ 0.2706 ) between total moisture storage, $w$ and total latent heat for air dehumidification. Experimental DVS and numerical simulation for water vapour sorption/desorption kinetics were conducted for the three new materials, in which the latter appeared to be slightly underestimated. This was consistent for most desiccants shown in Fig. 12 and Table 4, where the lack of a dynamic input for $w$ (time-response for water vapour adsorption), caused significant differences between both results. Additionally, Table 4 showed (see a, c, d, and g) that the major underestimations were largely attributed to a combination of adsorption kinetics (time-response) and hysteresis. This, for the case of MCM-41@165, was found to account for 52.4\% (average) of the total $w$ values at the third $\mathrm{RH}$ buffering cycle. Conversely, it was found that the numerical model accurately predicted EMC and found very good agreement with the 
experimental data taken from the water vapour isotherm. Further research is therefore needed for coupling both adsorption kinetics (i.e., adsorption time-response) and realistic scanning curve estimates within the hysteresis loop.

\section{Nomenclature}

$\rho$
$C_{\mathrm{p}}$
$\lambda(w)$
$\varphi$
$n$
$w=f(\varphi)$
$\mu(\varphi)$
$D_{\mathrm{w}}(w)$
$\mathrm{RH}$

$p_{\mathrm{v}} / p_{0}$
$H$
$h_{\mathrm{v}}$
$t$
$T$
$\delta_{\mathrm{p}}$

Bulk density $\mathrm{kg} \mathrm{\textrm {m } ^ { - 3 }}$

Specific heat capacity $\mathrm{J} \mathrm{kg}^{-1} \mathrm{~K}^{-1}$

Moisture-dependent thermal

conductivity $\mathrm{W} \mathrm{m}^{-1} \mathrm{~K}^{-1}$

Relative vapour pressure $\left(p_{\mathrm{v}} / p_{\text {sat }}\right)$

Bulk porosity $\mathrm{m}^{3} \mathrm{~m}^{-3}$

Water vapour sorption isotherm $\mathrm{kg} \mathrm{m}^{-3}$

Water vapour diffusion factor

Liquid water diffusivity $\mathrm{m}^{2} \mathrm{~s}^{-1}$

Relative humidity; where $\mathrm{RH}=\varphi \times$

$100 \%$

Partial pressure of water vapour

Total enthalpy $\mathrm{J} \mathrm{m}^{-3}$

Latent heat of phase change $\mathrm{J} \mathrm{kg}^{-1}$

Time s

Temperature $\mathrm{K}$

Vapour permeability $\mathrm{kg} \mathrm{m}^{-1} \mathrm{~s}^{-1} \mathrm{~Pa}$

\section{Suffixes}

interior

exterior

lower limit

upper limit

\section{Acknowledgements}

The authors wish to gratefully acknowledge the support of CONICYT for funding this research through the 'Programa de Formación de Capital Humano Avanzado, BECAS CHILE' Ministerio de Educación, Gobierno de Chile.

\section{References}

1 W. A. Belding, M. P. F. Delmas and W. D. Holeman, Appl.

Therm. Eng., 1996, 16, 447-459.

2 J. D. Chung and D.-Y. Lee, Int. J. Refrig., 2009, 32, 720-726.

3 S. P. Casey, M. R. Hall, S. C. E. Tsang and M. A. Khan, Build. Environ., 2013, 60, 24-36.

4 B. F. Yu, Z. B. Hu, M. Liu, H. L. Yang, Q. X. Kong and Y. H. Liu, Int. J. Refrig., 2009, 32, 3-20.

5 J. M. Calm, Int. J. Refrig., 2002, 25, 293-305.

6 J. T. McMullan, Int. J. Refrig., 2002, 25, 89-99.

7 S. B. Riffat, C. F. Afonso, A. C. Oliveira and D. A. Reay, Appl. Therm. Eng., 1997, 17, 33-42.

8 G. Lorentzen, Int. J. Refrig., 1995, 18, 190-197.

9 Adsorption air conditioning system, U.S. Pat., 5580 369, 1996.
10 Desiccant assisted air conditioning system, U.S. Pat., 5816065 , 1998.

11 A. A. Kinsara, M. M. Elsayed and O. M. Al-Rabghi, Appl. Therm. Eng., 1996, 16, 791-806.

12 Y. J. Dai, R. Z. Wang, H. F. Zhang and J. D. Yu, Appl. Therm. Eng., 2001, 21, 1185-1202.

13 N. Srivastava and I. Eames, Appl. Therm. Eng., 1998, 18, 707714.

14 K. Daou, R. Wang and Z. Xia, Renewable Sustainable Energy Rev., 2006, 10, 55-77.

15 D. La, Y. Dai, Y. Li, R. Wang and T. Ge, Renewable Sustainable Energy Rev., 2010, 14, 130-147.

16 L. Zhang and J. Niu, Appl. Therm. Eng., 2002, 22, 1347-1367.

17 N. C. Srivastava and I. W. Eames, Appl. Therm. Eng., 1998, 18, 707-714.

18 M. O'Kelly, M. E. Walter and J. R. Rowland, Energ. Build., 2015, 86, 45-57.

19 P. Dhar and S. Singh, Appl. Therm. Eng., 2001, 21, 119-134.

20 S. Jain, P. Dhar and S. Kaushik, Int. J. Refrig., 1995, 18, 287296.

21 J. Camargo, E. Godoy Jr and C. Ebinuma, J. Braz. Soc. Mech. Sci. Eng., 2005, 27, 243-247.

22 P. Mazzei, F. Minichiello and D. Palma, Appl. Therm. Eng., 2005, 25, 677-707.

23 P. Mazzei, F. Minichiello and D. Palma, Appl. Therm. Eng., 2002, 22, 545-560.

24 Materials for energy efficiency and thermal comfort in buildings, ed. M. R. Hall, CRC Press, Cambridge, 2010.

25 G. Panaras, E. Mathioulakis and V. Belessiotis, Energy, 2011, 36, 2399-2406.

26 G. Grossman, Sol. Energy, 2002, 72, 53-62.

27 C. A. Balaras, G. Grossman, H.-M. Henning, C. A. I. Ferreira, E. Podesser, L. Wang and E. Wiemken, Renewable Sustainable Energy Rev., 2007, 11, 299-314.

28 A. E. Kabeel, Renewable Energy, 2007, 32, 1842-1857.

29 M. Steeman, A. Janssens and M. de Paepe, Appl. Therm. Eng., 2009, 29, 2870-2875.

30 M. Goldsworthy and S. White, Int. J. Refrig., 2011, 34, 148-158. 31 S. Henninger, F. Schmidt and H.-M. Henning, Appl. Therm. Eng., 2010, 30, 1692-1702.

32 F. Ziegler, Int. J. Refrig., 2002, 25, 450-459.

33 R. Z. Wang and R. G. Oliveira, Prog. Energy Combust. Sci., 2006, 32, 424-458.

34 H. Demir, M. Mobedi and S. Ülkü, Renewable Sustainable Energy Rev., 2008, 12, 2381-2403.

35 J. Nie, L. Fang, G. Zhang, Y. Sheng, X. Kong, Y. Zhang and B. W. Olesen, Build. Environ., 2015, 85, 233-242.

36 E. Hürdoğan, O. Büyükalaca, M. T. Balta, A. Hepbasli and T. Yilmaz, Energy Convers. Manage., 2013, 69, 9-16.

37 X. Zheng, T. Ge and R. Wang, Energy, 2014, 74, 280-294.

38 M. R. Hall, S. C. E. Tsang, S. P. Casey, M. A. Khan and H. Yang, Acta Mater., 2012, 60, 89-101.

39 S. T. Meek, J. A. Greathouse and M. D. Allendorf, Adv. Mater., 2011, 23, 249-267.

40 H. Furukawa, N. Ko, Y. B. Go, N. Aratani, S. B. Choi, E. Choi, A. Ö. Yazaydin, R. Q. Snurr, M. O'Keeffe and J. Kim, Science, 2010, 329, 424-428. 
41 R. Banerjee, A. Phan, B. Wang, C. Knobler, H. Furukawa, M. O'Keeffe and O. M. Yaghi, Science, 2008, 319, 939-943.

42 J. L. C. Rowsell and O. M. Yaghi, Microporous Mesoporous Mater., 2004, 73, 3-14.

43 W. Sangchoom and R. Mokaya, J. Mater. Chem., 2012, 22, 18872-18878.

44 A. Corma, Q. Kan, M. T. Navarro, J. Pérez-Pariente and F. Rey, Chem. Mater., 1997, 9, 2123-2126.

45 A. Sayari and S. Hamoudi, Chem. Mater., 2001, 13, 31513168.

46 J. Lei, J. Fan, C. Yu, L. Zhang, S. Jiang, B. Tu and D. Zhao, Microporous Mesoporous Mater., 2004, 73, 121-128.

47 R. Collier, T. Cale and Z. Lavan, Advanced desiccant materials assessment, Enerscope, Inc, Glendale, AZ (USA), 1986.

48 J. Canivet, A. Fateeva, Y. Guo, B. Coasne and D. Farrusseng, Chem. Soc. Rev., 2014, 43(16), 5594-5617.

49 P. Küsgens, M. Rose, I. Senkovska, H. Fröde, A. Henschel, S. Siegle and S. Kaskel, Microporous Mesoporous Mater., 2009, 120, 325-330.

50 J. Ehrenmann, S. K. Henninger and C. Janiak, Eur. J. Inorg. Chem., 2011, 2011, 471-474.

51 S. K. Henninger, H. A. Habib and C. Janiak, J. Am. Chem. Soc., 2009, 131, 2776-2777.

52 H. Furukawa, F. Gándara, Y.-B. Zhang, J. Jiang, W. L. Queen, M. R. Hudson and O. M. Yaghi, J. Am. Chem. Soc., 2014, 136, 4369-4381.

53 A. Khutia, H. U. Rammelberg, T. Schmidt, S. Henninger and C. Janiak, Chem. Mater., 2013, 25, 790-798.
54 G. Akiyama, R. Matsuda, H. Sato, A. Hori, M. Takata and S. Kitagawa, Microporous Mesoporous Mater., 2012, 157, 8993.

55 Y. K. Seo, J. W. Yoon, J. S. Lee, Y. K. Hwang, C. H. Jun, J. S. Chang, S. Wuttke, P. Bazin, A. Vimont and M. Daturi, Adv. Mater., 2012, 24, 806-810.

56 F. S. Thomann, M. R. Hall, W. Sangchoom and R. Mokaya, Microporous Mesoporous Mater., 2015, 211, 113-123.

57 J. Rouquerol, F. Rouquerol and K. S. W. Sing, Absorption by powders and porous solids, Academic press, Marseille, 1998.

58 H. M. Künzel, Ph.D. Thesis, IRB-Verlag, 1995.

59 D. Zhao, J. Feng, Q. Huo, N. Melosh, G. H. Fredrickson, B. F. Chmelka and G. D. Stucky, Science, 1998, 279, 548-552.

60 M. Woloszyn and C. Rode, Build. Simulat. Int. J., 2008, 1, 524.

61 T. Kalamees and J. Vinha, Build. Environ., 2003, 38, 689-697. 62 Z. Pavlík and R. Černý, Energ. Build., 2008, 40, 673-678.

63 H. M. Künzel, A. Holm, D. Zirkelbach and A. N. Karagiozis, Sol. Energy, 2005, 78, 554-561.

64 B. EN, German version DIN EN, 2007, 15026.

65 Fraunhofer, WUFI Pro \& Plus®: PC-Program for coupled heat and mass transfer in building components, http:// www.wufi.de/index_e.html, (accessed 28/07/2015).

66 S. K. Henninger, F. Jeremias, H. Kummer and C. Janiak, Eur. J. Inorg. Chem., 2012, 2012, 2625-2634.

67 H. Naono, M. Hakuman, T. Tanaka, N. Tamura and K. Nakai, J. Colloid Interface Sci., 2000, 225, 411-420.

68 Z. Knez and Z. Novak, J. Chem. Eng. Data, 2001, 46, 858-860. 69 W. Wang, L. Wu, Z. Li, Y. Fang, J. Ding and J. Xiao, Drying Technol., 2013, 31, 1334-1345. 